\title{
On Soft Topological Spaces
}

\author{
D. N. Georgiou ${ }^{1, *}$, A. C. Megaritis ${ }^{2}$ and V. I. Petropoulos ${ }^{1}$ \\ ${ }^{1}$ University of Patras, Department of Mathematics, 26500 Patras, Greece \\ 2 Technological Educational Institute of Messolonghi, Department of Accounting, 30200 Messolonghi, Greece
}

Received: 20 Jan. 2013, Revised: 23 May. 2013, Accepted: 24 May. 2013

Published online: 1 Sep. 2013

\begin{abstract}
The classical mathematical theories have their difficulties which are pointed out in [18] for the solution complicated problems in engineering and environment. To overcome these difficulties, Molodtsov [18] introduced the concept of soft set as a new mathematical tool. Furthermore, D. Pei and D. Miao [22] showed that soft sets are a class of special information systems. In [9] for the soft set theory: new definitions, examples, new classes of soft sets, and properties for mappings between different classes of soft sets are introduced and studied. Moreover, the theory of soft topological spaces is investigated. This paper continues the study of the theory of soft topological spaces and presents for this theory new definitions, characterizations, and results concerning separation axioms, convergence, Cartesian product, soft $\theta$-topology, and soft $\theta$-continuity.
\end{abstract}

Keywords: Soft set theory, soft topology.

\section{Preliminaries}

In 1999 D. Molodtsov (see [18]) introduced the notion of soft set. Later, he applied this theory to several directions (see [19], [20], and [21]).

The soft set theory has been applied to many different fields (see, for example, [1], [2], [4], [5], [7], [8], [11], [12], [13], [14], [15], [16], [22], [25], [27]).

In 2011 and 2012 few researches (see, for example, [3], [6], [10], [17], [23], [24], [26]) introduced and studied the notion of soft topological spaces which are defined over an initial universe with a fixed set of parameters.

It is known that topology is an important area of mathematics with many applications in the domains of computer science and physical sciences. Soft topology is a relatively new and promising domain which can lead to the development of new mathematical models and innovative approaches that will significantly contribute to the solution of complex problems in natural sciences.

The paper is organized as follows. In section 2 we give known basic notions and results concerning the theory of soft sets and soft topological spaces. In section 3 we present separation axioms and we investigate the notion of convergence. In section 4 the Cartesian product of two soft topological spaces is studied. In section 5 we introduce and study notions concerning the soft $\theta$-open sets, the soft $\theta$-closed sets, and the soft $\theta$-continuity. In section 6 we give some questions on soft topological spaces. The last section of this paper is the conclusion.

\section{Basic known notions for the theory of soft topological spaces}

Definition 2.1 (see [18]) Let $X$ be an initial universe set, $\mathscr{P}(X)$ the power set of $X$, that is the set of all subsets of $X$, and $A$ a set of parameters. A pair $(F, A)$, where $F$ is a map from $A$ to $\mathscr{P}(X)$, is called a soft set over $X$.

In what follows by $\operatorname{SS}(X, A)$ we denote the family of all soft sets $(F, A)$ over $X$.

Definition 2.2 (see [18]) Let $(F, A),(G, A) \in \mathrm{SS}(X, A)$. We say that the pair $(F, A)$ is a soft subset of $(G, A)$ if $F(p) \subseteq$ $G(p)$, for every $p \in A$. Symbolically, we write $(F, A) \sqsubseteq$ $(G, A)$. Also, we say that the pairs $(F, A)$ and $(G, A)$ are soft equal if $(F, A) \sqsubseteq(G, A)$ and $(G, A) \sqsubseteq(F, A)$. Symbolically, we write $(F, A)=(G, A)$.

Definition 2.3 (see, for example, [18] and [26]) Let $I$ be an arbitrary index set and $\left\{\left(F_{i}, A\right): i \in I\right\} \subseteq \mathrm{SS}(X, A)$. The soft union of these soft sets is the soft set $(F, A) \in \mathrm{SS}(X, A)$, where the map $F: A \rightarrow \mathscr{P}(X)$ defined as follows: $F(p)=$ $\cup\left\{F_{i}(p): i \in I\right\}$, for every $p \in A$. Symbolically, we write

$$
(F, A)=\sqcup\left\{\left(F_{i}, A\right): i \in I\right\} .
$$

\footnotetext{
*Corresponding author e-mail: georgiou@math.upatras.gr
} 
Definition 2.4 (see, for example, [18] and [26]) Let $I$ be an arbitrary index set and $\left\{\left(F_{i}, A\right): i \in I\right\} \subseteq \operatorname{SS}(X, A)$. The soft intersection of these soft sets is the soft set $(F, A) \in \mathrm{SS}(X, A)$, where the map $F: A \rightarrow \mathscr{P}(X)$ defined as follows: $F(p)=\cap\left\{F_{i}(p): i \in I\right\}$, for every $p \in A$. Symbolically, we write

$$
(F, A)=\sqcap\left\{\left(F_{i}, A\right): i \in I\right\}
$$

Definition 2.5 (see, for example, [2] and [26]) Let $(F, A) \in \mathrm{SS}(X, A)$. The soft complement of $(F, A)$ is the soft set $(H, A) \in \mathrm{SS}(X, A)$, where the map $H: A \rightarrow \mathscr{P}(X)$ defined as follows: $H(p)=X \backslash F(p)$, for every $p \in A$. Symbolically, we write

$$
(H, A)=(F, A)^{c} .
$$

Definition 2.6 (see [18]) The soft set $(F, A) \in \mathrm{SS}(X, A)$, where $F(p)=\emptyset$, for every $p \in A$ is called the $A$-null soft set of $\operatorname{SS}(X, A)$ and denoted by $\mathbf{0}_{A}$. The soft set $(F, A) \in$ $\mathrm{SS}(X, A)$, where $F(p)=X$, for every $p \in A$ is called the $A$-absolute soft set of $\operatorname{SS}(X, A)$ and denoted by $\mathbf{1}_{A}$.

Definition 2.7 (see [26]) Let $X$ and $Y$ be two initial universe sets, $A$ and $B$ two sets of parameters, $f: X \rightarrow Y$, and $e: A \rightarrow B$. Then, by $\Phi_{f e}$ we denote the map from $\mathrm{SS}(X, A)$ to $\operatorname{SS}(Y, B)$ for which:

(1) If $(F, A) \in \mathrm{SS}(X, A)$, then the image of $(F, A)$ under $\Phi_{f e}$, denoted by $\Phi_{f e}(F, A)$, is the soft set $(G, B) \in \operatorname{SS}(Y, B)$ such that

$$
G\left(p_{Y}\right)=\left\{\begin{array}{l}
\cup\left\{f(F(p)): p \in e^{-1}\left(\left\{p_{Y}\right\}\right)\right\} \\
\text { if } e^{-1}\left(\left\{p_{Y}\right\}\right) \neq \emptyset \\
\emptyset, \text { if } e^{-1}\left(\left\{p_{Y}\right\}\right)=\emptyset
\end{array}\right.
$$

for every $p_{Y} \in B$.

(2) If $(G, B) \in \mathrm{SS}(Y, B)$, then the inverse image of $(G, B)$ under $\Phi_{f e}$, denoted by $\Phi_{f e}^{-1}(G, B)$, is the soft set $(F, A) \in \mathrm{SS}(X, A)$ such that $F(p)=f^{-1}(G(e(p)))$, for every $p \in A$.

Proposition 2.8 (see Propositions 2.18 and 2.19 of [9]) Let $(F, A),\left(F_{1}, A\right) \in \mathrm{SS}(X, A),(G, B),\left(G_{1}, B\right) \in \mathrm{SS}(Y, B)$. The following statements are true:

(1) If $(F, A) \sqsubseteq\left(F_{1}, A\right)$, then $\Phi_{f e}(F, A) \sqsubseteq \Phi_{f e}\left(F_{1}, A\right)$.

(2) If $(G, B) \sqsubseteq\left(G_{1}, B\right)$, then $\Phi_{f e}^{-1}(G, B) \sqsubseteq \Phi_{f e}^{-1}\left(G_{1}, B\right)$.

(3) $(F, A) \sqsubseteq \Phi_{f e}^{-1}\left(\Phi_{f e}(F, A)\right)$.

(4) $\Phi_{f e}\left(\Phi_{f e}^{-1}(G, B)\right) \sqsubseteq(G, B)$.

(5) $\Phi_{f e}^{-1}\left((G, B)^{c}\right)=\left(\Phi_{f e}^{-1}(G, B)\right)^{c}$.

(6) $\Phi_{f e}\left((F, A) \sqcup\left(F_{1}, A\right)\right)=\Phi_{f e}(F, A) \sqcup \Phi_{f e}\left(F_{1}, A\right)$.

(7) $\Phi_{f e}\left((F, A) \sqcap\left(F_{1}, A\right)\right) \sqsubseteq \Phi_{f e}(F, A) \sqcap \Phi_{f e}\left(F_{1}, A\right)$.

(8) $\Phi_{f e}^{-1}\left((G, B) \sqcup\left(G_{1}, B\right)\right)=\Phi_{f e}^{-1}(G, B) \sqcup \Phi_{f e}^{-1}\left(G_{1}, B\right)$.

(9) $\Phi_{f e}^{-1}\left((G, B) \sqcap\left(G_{1}, B\right)\right)=\Phi_{f e}^{-1}(G, B) \sqcap \Phi_{f e}^{-1}\left(G_{1}, B\right)$.
Definition 2.9 (see, for example, [26]) Let $X$ be an initial universe set, $A$ a set of parameters, and $\tau \subseteq \mathrm{SS}(X, A)$. We say that the family $\tau$ defines a soft topology on $X$ if the following axioms are true:

(1) $\mathbf{0}_{A}, \mathbf{1}_{A} \in \tau$.

(2) If $(G, A),(H, A) \in \tau$, then $(G, A) \sqcap(H, A) \in \tau$.

(3) If $\left(G_{i}, A\right) \in \tau$ for every $i \in I$, then

$$
\sqcup\left\{\left(G_{i}, A\right): i \in I\right\} \in \tau .
$$

The triplet $(X, \tau, A)$ is called a soft topological space or soft space. The members of $\tau$ are called soft open sets in $X$. Also, a soft set $(F, A)$ is called soft closed if the complement $(F, A)^{c}$ belongs to $\tau$. The family of soft closed sets is denoted by $\tau^{c}$.

Definition 2.10 (see [9]) Let $(X, \tau, A)$ be a soft topological space, $a \in A$, and $x \in X$. We say that a soft set $(G, A) \in \tau$ is an a-soft open neighborhood of $x$ in $(X, \tau, A)$ if $x \in G(a)$.

Proposition 2.11 (see [9]) Let $(X, \tau, A)$ be a soft topological space. Then, $(G, A) \in \tau$ if and only if for every $a \in A$ and $x \in G(a)$ there exists an $a$-soft open neighborhood $\left(G_{(a, x)}, A\right)$ of $x$ in $(X, \tau, A)$ such that $\left(G_{(a, x)}, A\right) \sqsubseteq(G, A)$.

Definition 2.12 (see [24]) Let $(X, \tau, A)$ be a soft topological space. The soft closure $\mathrm{Cl}(F, A)$ of $(F, A) \in \mathrm{SS}(X, A)$ is the soft set

$$
\sqcap\left\{(Q, A) \in \tau^{c}:(F, A) \sqsubseteq(Q, A)\right\} .
$$

Remark. (See, for example, [26]) Let $(X, \tau, A)$ be a soft topological space and $(F, A),(G, A) \in \mathrm{SS}(X, A)$. We recall the following properties :

(1) $(F, A) \in \tau^{c}$ if and only if $\mathrm{Cl}(F, A)=(F, A)$.

(2) If $(F, A) \sqsubseteq(G, A)$, then $\mathrm{Cl}(F, A) \sqsubseteq \mathrm{Cl}(G, A)$.

Definition 2.13 (see [9]) Let $(X, \tau, A)$ be a soft topological space and $a \in A$. A point $x \in X$ is said to be an a-cluster point of $(F, A) \in \mathrm{SS}(X, A)$ if for every $a$-soft open neighborhood $(G, A)$ of $x$ we have $(F, A) \sqcap(G, A) \neq \mathbf{0}_{A}$. The set of all $a$-cluster points of $(F, A)$ is denoted by $\operatorname{cl}(F, a)$.

Proposition 2.14 (see [9]) Let $(X, \tau, A)$ be a soft space and $(F, A) \in \operatorname{SS}(X, A)$. Then, $\operatorname{Cl}(F, A)=\left(R_{F, A}, A\right)$, where the map $R_{F, A}: A \rightarrow \mathscr{P}(X)$ defined as follows: $R_{F, A}(p)=$ $F(p) \cup \operatorname{cl}(F, p)$, for every $p \in A$.

Remark. Obviously, $F(p) \subseteq \operatorname{cl}(F, p)$, for every $p \in A$. Thus, in Proposition 2.14 we have $R_{F, A}(p)=\operatorname{cl}(F, p)$, for every $p \in A$.

Definition 2.15 (see, for example, [26]) Let $(X, \tau, A)$ be a soft topological space. A family $\mathscr{B} \subseteq \tau$ is called a base for $(X, \tau, A)$ if for every soft open set $(\bar{G}, A) \neq \mathbf{0}_{A}$, there exist $\left(G_{i}, A\right) \in \mathscr{B}, i \in I$, such that

$$
(G, A)=\sqcup\left\{\left(G_{i}, A\right): i \in I\right\} .
$$


Proposition 2.16 (see [9]) Let $(X, \tau, A)$ be a soft topological space. Then, a family $\mathscr{B} \subseteq \tau$ is a base for $(X, \tau, A)$ if and only if for every $a \in A, x \in X$, and every $a$-soft open neighborhood $(G, A)$ of $x$ there exists an $a$-soft open neighborhood $\left(G_{(a, x)}, A\right)$ of $x$ such that $\left(G_{(a, x)}, A\right) \in \mathscr{B}$ and $\left(G_{(a, x)}, A\right) \sqsubseteq(G, A)$.

Definition 2.17 (see [9]) Let $\left(X, \tau_{X}, A\right)$ and $\left(Y, \tau_{Y}, B\right)$ be two soft topological spaces, $x \in X$, and $e: A \rightarrow B$. A map $f: X \rightarrow Y$ is called soft e-continuous at the point $x$ if for every $a \in A$ and every $e(a)$-soft open neighborhood $(G, B)$ of $f(x)$ in $\left(Y, \tau_{Y}, B\right)$ there exists an $a$-soft open neighborhood $(F, A)$ of $x$ in $\left(X, \tau_{X}, A\right)$ such that

$$
\Phi_{f e}(F, A) \sqsubseteq(G, B) .
$$

If the map $f$ is soft $e$-continuous at any point $x \in X$, then we say that the map $f$ is soft e-continuous.

Proposition 2.18 (see [9]) Let $\left(X, \tau_{X}, A\right)$ and $\left(Y, \tau_{Y}, B\right)$ be two soft topological spaces and $e: A \rightarrow B$. Then, the following statements are equivalent:

(1) The map $f: X \rightarrow Y$ is soft $e$-continuous.

(2) $\Phi_{f e}^{-1}(G, B) \in \tau_{X}$, for every $(G, B) \in \tau_{Y}$.

(3) $\Phi_{f e}^{-1}(Q, B) \in \tau_{X}^{c}$, for every $(Q, B) \in \tau_{Y}^{c}$.

(4) $\Phi_{f e}(\mathrm{Cl}(F, A)) \sqsubseteq \mathrm{Cl}\left(\Phi_{f e}(F, A)\right)$, for every $(F, A) \in \mathrm{SS}(X, A)$.

Proposition 2.19 (see [9]) Let $\left(X, \tau_{X}, A\right)$ and $\left(Y, \tau_{Y}, B\right)$ be two soft topological spaces, $\mathscr{B}_{Y}$ a base for $\left(Y, \tau_{Y}, B\right)$, and $e: A \rightarrow B$. Then, the following statements are equivalent:

(1) The map $f: X \rightarrow Y$ is soft $e$-continuous.

(2) $\Phi_{f e}^{-1}(G, B) \in \tau_{X}$, for every $(G, B) \in \mathscr{B}_{Y}$.

\section{Separation axioms and convergence}

Notation 3.1 Let $(F, A) \in \operatorname{SS}(X, A), a \in A$, and $x \in X$. In what follows we write $x \in \in_{a}(F, A)$ (respectively, $x \notin_{a}(F, A)$ ) if and only if $x \in F(a)$ (respectively, $x \notin F(a))$.

Definition 3.2 A soft topological space $(X, \tau, A)$ is called a soft $\mathrm{T}_{0}$-space if for every distinct points $x, y$ of $X$ and for every $a \in A$ there exists a soft open set $(G, A)$ such that either $x \in_{a}(G, A)$ and $y \notin_{a}(G, A)$ or $x \notin_{a}(G, A)$ and $y \in_{a}(G, A)$.

Definition 3.3 A soft topological space $(X, \tau, A)$ is called a soft $\mathrm{T}_{1}$-space if for every distinct points $x, y$ of $X$ and for every $a \in A$ there exists a soft open set $(G, A)$ such that $x \in_{a}(G, A)$ and $y \notin_{a}(G, A)$.

Proposition 3.4 Let $(X, \tau, A)$ be a soft topological space. If for every $x \in X$ we have $\left(F_{x}, A\right) \in \tau^{c}$, where $F_{x}(p)=\{x\}$, for every $p \in A$, then $(X, \tau, A)$ is a soft $\mathrm{T}_{1}$-space.

Proof. We suppose that for every $x \in X$ we have $\left(F_{x}, A\right) \in \tau^{c}$. We prove that the triplet $(X, \tau, A)$ is a soft
$\mathrm{T}_{1}$-space. Let $x$ and $y$ be two distinct points of $X$ and $a \in A$. Then, $\left(F_{y}, A\right) \in \tau^{c}$ and, therefore, $\left(F_{y}, A\right)^{c} \in \tau$. Since $x \in X \backslash\{y\}=X \backslash F_{y}(a)$, we have $x \in \in_{a}\left(F_{y}, A\right)^{c}$. Also, $y \notin_{a}\left(F_{y}, A\right)^{c}$. Thus, the triplet $(X, \tau, A)$ is a soft $\mathrm{T}_{1}$-space.

Definition 3.5 A soft topological space $(X, \tau, A)$ is called a soft $\mathrm{T}_{2}$-space if for every distinct points $x, y$ of $X$ and for every $a \in A$ there exist two soft open sets $(G, A)$ and $(H, A)$ such that $x \in_{a}(G, A), y \in_{a}(H, A)$, and $G(a) \cap H(a)=\emptyset$.

Remark 3.6 Every soft $\mathrm{T}_{2}$-space is a soft $\mathrm{T}_{1}$-space and every soft $\mathrm{T}_{1}$-space is a soft $\mathrm{T}_{0}$-space.

Example 3.7 (1) Let $X=\{x, y, z\}$ and $A=\{0,1\}$. We consider the following soft sets $\left(F_{i}, A\right), i=1,2, \ldots, 6$, over $X$ defined as follows:

$$
\begin{gathered}
F_{1}(a)=\left\{\begin{array}{l}
\{x\}, \text { if } a=0, \\
\{z\}, \text { if } a=1,
\end{array} \quad F_{2}(a)=\left\{\begin{array}{l}
\{y\}, \text { if } a=0, \\
\{x\}, \text { if } a=1,
\end{array}\right.\right. \\
F_{3}(a)=\left\{\begin{array}{l}
\{z\}, \text { if } a=0, \\
\{y\}, \text { if } a=1,
\end{array} F_{4}(a)=\left\{\begin{array}{l}
\{x, y\}, \text { if } a=0, \\
\{x, z\}, \text { if } a=1,
\end{array}\right.\right. \\
F_{5}(a)=\left\{\begin{array}{l}
\{x, z\}, \text { if } a=0, \\
\{y, z\}, \text { if } a=1,
\end{array} \quad F_{6}(a)=\left\{\begin{array}{l}
\{y, z\}, \text { if } a=0, \\
\{x, y\}, \text { if } a=1 .
\end{array}\right.\right.
\end{gathered}
$$

Then, the triplet $(X, \tau, A)$, where

$$
\tau=\left\{\left(F_{i}, A\right): i=1,2, \ldots, 6\right\} \cup\left\{\mathbf{0}_{A}, \mathbf{1}_{A}\right\}
$$

is a soft $\mathrm{T}_{2}$-space and, therefore, soft $\mathrm{T}_{1}$-space and soft $\mathrm{T}_{0}$-space.

(2) Let $X=\{1,2, \ldots\}, A=\{0,1,2\}$, and

$$
\tau=\left\{\left(G_{n}, A\right): n \in\{1,2, \ldots\}\right\} \cup\left\{\mathbf{0}_{A}, \mathbf{1}_{A}\right\},
$$

such that $G_{n}: A \rightarrow \mathscr{P}(X)$, where

$$
G_{n}(p)=\{n, n+1, \ldots\},
$$

for every $p \in A$. The triplet $(X, \tau, A)$ is a soft topological space.

Let $x$ and $y$ be two distinct points of $X$ and $a \in A$. We suppose that $y<x$. Then, $x \in\{x, x+1, \ldots\}=G_{x}(a)$ and $y \notin\{x, x+1, \ldots\}$. This means that $x \in_{a}\left(G_{x}, A\right)$ and $y \notin_{a}$ $\left(G_{x}, A\right)$. Thus, the soft topological space $(X, \tau, A)$ is a soft $\mathrm{T}_{0}$-space. Also, we observe that this soft topological space is neither soft $\mathrm{T}_{1}$-space nor soft $\mathrm{T}_{2}$-space. and

(3) Let $(X, t)$ be a topological space, $A$ a nonempty set,

$$
\tau=\left\{\left(G_{U}, A\right): U \in t\right\},
$$

such that $G_{U}: A \rightarrow \mathscr{P}(X)$, where $G_{U}(p)=U$, for every $p \in A$. The triplet $(X, \tau, A)$ is a soft topological space. Then, the soft topological space $(X, \tau, A)$ is a soft $\mathrm{T}_{i}$-space if and only if the topological space $(X, t)$ is a $\mathrm{T}_{i}$-space, $i \in\{0,1,2\}$.

Definition 3.8 A soft topological space $(X, \tau, A)$ is called a soft $\mathrm{T}_{3}$-space if for every point $x \in X$, for every $a \in A$, 
and for every soft closed set $(Q, A)$ such that $x \notin_{a}(Q, A)$ there exist two soft open sets $(G, A)$ and $(H, A)$ such that $x \in_{a}(G, A), Q(a) \subseteq H(a)$, and $G(a) \cap H(a)=\emptyset$.

Example 3.9 Let $X=\{x, y, z\}$ and $A=\{0,1\}$. We consider the following soft sets $(G, A)$ and $(H, A)$ over $X$ defined as follows:

$$
G(a)=\left\{\begin{array}{l}
\{x\}, \text { if } a=0, \\
\{x, y\}, \text { if } a=1,
\end{array} H(a)=\left\{\begin{array}{l}
\{y, z\}, \text { if } a=0 \\
\{z\}, \text { if } a=1 .
\end{array}\right.\right.
$$

Then, the triplet $(X, \tau, A)$, where

$$
\tau=\left\{\mathbf{0}_{A}, \mathbf{1}_{A},(G, A),(H, A)\right\}
$$

is a soft topological space. We observe that the soft topological space $(X, \tau, A)$ is a soft $\mathrm{T}_{3}$-space but it is not a soft $\mathrm{T}_{i}$-space for $i=0,1,2$.

The proof of the following proposition is straightforward verification of the definitions.

Proposition 3.10 Let $(X, \tau, A)$ be a soft $\mathrm{T}_{3}$-space such that for every $x \in X$ and every $a_{0} \in A$ the soft set $\left(F_{x}^{a_{0}}, A\right)$ defined as follows:

$$
F_{x}^{a_{0}}(a)=\left\{\begin{array}{l}
\{x\}, \text { if } a=a_{0} \\
\emptyset, \text { if } a \neq a_{0},
\end{array}\right.
$$

is a soft closed set. Then, the soft topological space $(X, \tau, A)$ is a $\mathrm{T}_{2}$-space.

Proposition 3.11 Let $(X, \tau, A)$ be a soft topological space. If for every $x \in X$, for every $a \in A$, and for every $a$-soft open neighborhood $(F, A)$ of $x$ there exists an $a$-soft open neighborhood $(G, A)$ of $x$ such that

$$
x \in G(a) \subseteq \operatorname{cl}(G, a) \subseteq F(a),
$$

then $(X, \tau, A)$ is a soft $\mathrm{T}_{3}$-space.

Proof. Let $x \in X, a \in A$, and $(Q, A) \in \tau^{c}$ such that $x \notin_{a}$ $(Q, A)$. Then, $x \in_{a}(Q, A)^{c}$ and $(Q, A)^{c} \in \tau$. This means that the soft set $(Q, A)^{c}$ is an $a$-soft open neighborhood of $x$. By assumption there exists an $a$-soft open neighborhood $(G, A)$ of $x$ such that

$$
x \in G(a) \subseteq \operatorname{cl}(G, a) \subseteq X \backslash Q(a) .
$$

We consider the soft set $\mathrm{Cl}(G, A)^{c}$. By Proposition 2.14 and Definition 2.5, $\operatorname{Cl}(G, A)^{c}=(H, A)$, where $H(p)=X \backslash \operatorname{cl}(G, p)$, for every $p \in A$. We observe that $(H, A) \in \tau, Q(a) \subseteq H(a)$, and $G(a) \cap H(a)=\emptyset$. Thus, the triplet $(X, \tau, A)$ is a soft $\mathrm{T}_{3}$-space.

Definition 3.12 (see [24]) Let $(X, \tau, A)$ be a soft topological space and $Y$ a nonempty subset of $X$. Then, the soft subspace $\left(Y, \tau_{Y}, A\right)$ defined as follows: $\left(G^{Y}, A\right) \in \tau_{Y}$ if and only if there exists $(G, A) \in \tau$ such that $G^{Y}(p)=Y \cap G(p)$, for every $p \in A$.
Remark. (see [24]) A soft set $\left(F^{Y}, A\right)$ is soft closed if and only if there exists a soft closed set $(F, A)$ such that $F^{Y}(p)=Y \cap F(p)$, for every $p \in A$.

Proposition 3.13 Let $(X, \tau, A)$ be a soft $\mathrm{T}_{i}$-space, where $i=0,1,2,3$. Then, every soft subspace $\left(Y, \tau_{Y}, A\right)$ of the soft space $(X, \tau, A)$ is a soft $\mathrm{T}_{i}$-space.

Proof. (i=0) Let $y_{1}$ and $y_{2}$ be two distinct points of $Y$ and $a \in A$. Since $(X, \tau, A)$ is a soft $\mathrm{T}_{0}$-space, there exists $(G, A) \in \tau$ such that either $y_{1} \in_{a}(G, A)$ and $y_{2} \notin_{a}(G, A)$ or $y_{1} \notin_{a}(G, A)$ and $y_{2} \in_{a}(G, A)$. Without loss of generality we suppose that $y_{1} \in_{a}(G, A)$ and $y_{2} \notin_{a}(G, A)$. We consider the map $G^{Y}: A \rightarrow \mathscr{P}(Y)$ defined as follows: $G^{Y}(p)=Y \cap G(p)$, for every $p \in A$. Then, $\left(G^{Y}, A\right) \in \tau_{Y}$. We observe that $y_{1} \in_{a}\left(G^{Y}, A\right)$ and $y_{2} \notin_{a}\left(G^{Y}, A\right)$. Thus, the triplet $\left(Y, \tau_{Y}, A\right)$ is a soft $\mathrm{T}_{0}$-space.

(i=1) Let $y_{1}$ and $y_{2}$ be two distinct points of $Y$ and $a \in A$. Since $(X, \tau, A)$ is a soft $\mathrm{T}_{1}$-space, there exists $(G, A) \in \tau$ such that $y_{1} \in_{a}(G, A)$ and $y_{2} \notin_{a}(G, A)$. We consider the map $G^{Y}: A \rightarrow \mathscr{P}(Y)$ defined as follows: $G^{Y}(p)=Y \cap G(p)$, for every $p \in A$. Then, $\left(G^{Y}, A\right) \in \tau_{Y}$, $y_{1} \in_{a}\left(G^{Y}, A\right)$, and $y_{2} \notin_{a}\left(G^{Y}, A\right)$. This means that the triplet $\left(Y, \tau_{Y}, A\right)$ is a soft $\mathrm{T}_{1}$-space.

(i=2) Let $y_{1}$ and $y_{2}$ be two distinct points of $Y$ and $a \in A$. Since $(X, \tau, A)$ is a soft $\mathrm{T}_{2}$-space, there exist $(G, A) \in \tau,(H, A) \in \tau$ such that $x \in_{a}(G, A), y \in_{a}(H, A)$, and $G(a) \cap H(a)=\emptyset$. We consider the maps $G^{Y}: A \rightarrow \mathscr{P}(Y)$ and $H^{Y}: A \rightarrow \mathscr{P}(Y)$ defined as follows: $G^{Y}(p)=Y \cap G(p)$ and $H^{Y}(p)=Y \cap H(p)$, for every $p \in A$. Then, $\left(G^{Y}, A\right) \in \tau_{Y},\left(H^{Y}, A\right) \in \tau_{Y}, y_{1} \in a\left(G^{Y}, A\right)$, $y_{2} \in_{a}\left(H^{Y}, A\right)$, and $G^{Y}(a) \cap H^{Y}(a)=\emptyset$. Thus, the triplet $\left(Y, \tau_{Y}, A\right)$ is a soft $\mathrm{T}_{2}$-space.

(i=3) Let $y \in Y, a \in A$, and $\left(Q^{Y}, A\right) \in \tau_{Y}^{c}$ such that $y \notin_{a}$ $\left(Q^{Y}, A\right)$. Then, there exists $(Q, A) \in \tau^{c}$ such that $Q^{Y}(p)=$ $Y \cap Q(p)$, for every $p \in A$. Obviously, $y \notin_{a}(Q, A)$. Since $(X, \tau, A)$ is a soft $\mathrm{T}_{3}$-space, there exist $(G, A) \in \tau,(H, A) \in$ $\tau$ such that $y \in_{a}(G, A), Q(a) \subseteq H(a)$, and $G(a) \cap H(a)=$ $\emptyset$. We consider the maps $G^{Y}: A \rightarrow \mathscr{P}(Y)$ and $H^{Y}: A \rightarrow$ $\mathscr{P}(Y)$ defined as follows: $G^{Y}(p)=Y \cap G(p)$ and $H^{Y}(p)=$ $Y \cap H(p)$, for every $p \in A$. Then, $\left(G^{Y}, A\right) \in \tau_{Y},\left(H^{Y}, A\right) \in$ $\tau_{Y}, y \in a\left(G^{Y}, A\right), Q^{Y}(a) \subseteq H^{Y}(a)$, and $G^{Y}(a) \cap H^{Y}(a)=\emptyset$. Thus, the triplet $\left(Y, \tau_{Y}, A\right)$ is a soft $\mathrm{T}_{3}$-space.

Definition 3.14 Let $(X, \tau, A)$ be a soft topological space. A point $x$ of $X$ is called soft-limit of a net $S=\left\{x_{\lambda}, \lambda \in \Lambda\right\}$ of $X$ if for every $a \in A$ and for every $a$-soft open neighborhood $(G, A)$ of $x$ there exists $\lambda_{0} \in \Lambda$ such that $x_{\lambda} \in_{a}(G, A)$ for every $\lambda \geq \lambda_{0}$. In this case we say that the net $S$ soft converges to $x$. The set of all soft limits of the net $S$ is denoted by $\operatorname{s-lim}(S)$. When the net $S$ has exactly one soft $\operatorname{limit} x$, then we write $\operatorname{s-lim}(S)=x$.

Proposition 3.15 Let $(X, \tau, A)$ be a soft $\mathrm{T}_{2}$-space, $S=\left\{x_{\lambda}, \lambda \in \Lambda\right\}$ a net of $X$, and $x, y \in \mathrm{s}-\lim (S)$. Then, $x=y$.

Proof. We suppose that $x \neq y$ and let $a \in A$. By assumption there exist two soft open sets $(G, A)$ and $(H, A)$ such that $x \in_{a}(G, A), y \in_{a}(H, A)$, and $G(a) \cap H(a)=\emptyset$. Since $x \in$ 
$\mathrm{s}-\lim (S)$, there exists $\lambda_{1} \in \Lambda$ such that $x_{\lambda} \in \in_{a}(G, A)$ for every $\lambda \geqslant \lambda_{1}$. Also, since $y \in \operatorname{s-lim}(S)$, there exists $\lambda_{2} \in \Lambda$ such that $x_{\lambda} \in_{a}(H, A)$ for every $\lambda \geqslant \lambda_{2}$. Let $\lambda_{0} \in \Lambda$ such that $\lambda_{0} \geqslant \lambda_{1}$ and $\lambda_{0} \geqslant \lambda_{2}$. Then, for every $\lambda \geqslant \lambda_{0}$ we have $x_{\lambda} \in_{a}(G, A)$ and $x_{\lambda} \in_{a}(H, A)$, which is a contradiction.

Proposition 3.16 Let $(X, \tau, A)$ be a soft topological space, $(F, A) \in \mathrm{SS}(\mathrm{X}, \mathrm{A})$, and $a \in A$. If there exists a net $S=\left\{x_{\lambda}, \lambda \in \Lambda\right\}$ of $X$ such that $x_{\lambda} \in a(F, A)$, for every $\lambda \in \Lambda$, and $x \in \mathrm{s}-\lim (S)$, then $x \in \in_{a} \mathrm{Cl}(F, A)$.

Proof. Let $S=\left\{x_{\lambda}, \lambda \in \Lambda\right\}$ be a net of $X$ such that $x_{\lambda} \in_{a}(F, A)$, for every $\lambda \in \Lambda$. By Proposition 2.14, it suffices to prove that $x \in \operatorname{cl}(F, a)$. Let $(G, A)$ be an arbitrary $a$-soft open neighborhood of $x$. Since $x \in \mathrm{s}-\lim (S)$, there exists $\lambda_{0} \in \Lambda$ such that $x_{\lambda} \in_{a}(G, A)$ for every $\lambda \geqslant \lambda_{0}$. Thus, $x_{\lambda_{0}} \in F(a) \cap G(a)$ and, therefore, $(F, A) \sqcap(G, A) \neq \mathbf{0}_{A}$. This means that $x \in \operatorname{cl}(F, a)$.

Proposition 3.17 Let $\left(X, \tau_{X}, A\right)$ and $\left(Y, \tau_{Y}, A\right)$ be two soft spaces, $x \in X$, and $e$ a map of $A$ onto $B$. If the map $f$ : $X \rightarrow Y$ is soft $e$-continuous at the point $x$, then for every net $S=\left\{x_{\lambda}, \lambda \in \Lambda\right\}$ of $X$ which soft converges to $x$ in $\left(X, \tau_{X}, A\right)$ we have that the net $\left\{f\left(x_{\lambda}\right), \lambda \in \Lambda\right\}$ of $Y$ soft converges to $f(x)$ in $\left(Y, \tau_{Y}, B\right)$.

Proof. Let $f: X \rightarrow Y$ be a soft $e$-continuous map at $x$ and $S=\left\{x_{\lambda}, \lambda \in \Lambda\right\}$ a net of $X$ which soft converges to $x$ in $\left(X, \tau_{X}, A\right)$. We prove that the net $\left\{f\left(x_{\lambda}\right), \lambda \in \Lambda\right\}$ of $Y$ soft converges to $f(x)$ in $\left(Y, \tau_{Y}, B\right)$. Let $b \in B$ and $(G, B)$ be a $b$-soft open neighborhood of $f(x)$ in $\left(Y, \tau_{Y}, B\right)$. Let $a \in$ $e^{-1}(\{b\})$. Since $f$ is soft $e$-continuous at the point $x$, there exists an $a$-soft open neighborhood $(F, A)$ of $x$ in $\left(X, \tau_{X}, A\right)$ such that $\Phi_{f e}(F, A) \sqsubseteq(G, B)$. Also, since $S$ soft converges to $x$, there exists $\lambda_{0} \in \Lambda$ such that $x_{\lambda} \in_{a}(F, A)$ for every $\lambda \geqslant \lambda_{0}$.

Let $\lambda \geqslant \lambda_{0}$. Then, $x_{\lambda} \in F(a)$ and, therefore,

$$
\begin{aligned}
f\left(x_{\lambda}\right) \in f(F(a)) & \subseteq \bigcup\left\{f(F(p)): p \in e^{-1}(\{b\})\right\} \\
& \subseteq G(b) .
\end{aligned}
$$

Thus, $f\left(x_{\lambda}\right) \in_{b}(G, B)$. This means that the net

$$
\left\{f\left(x_{\lambda}\right), \lambda \in \Lambda\right\}
$$

of $Y$ soft converges to $f(x)$ in $\left(Y, \tau_{Y}, B\right)$.

\section{Cartesian product of two soft topological spaces}

Definition 4.1 (see [23]) Let $(F, A) \in \mathrm{SS}(X, A)$ and $(G, B) \in \mathrm{SS}(Y, B)$. The Cartesian product of $(F, A)$ and $(G, B)$ is the soft set

$$
(H, A \times B) \in \mathrm{SS}(X \times Y, A \times B),
$$

where the map $H: A \times B \rightarrow \mathscr{P}(X \times Y)$ defined as follows:

$$
H(a, b)=F(a) \times G(b), \text { for every }(a, b) \in A \times B .
$$

Symbolically, we write $(H, A \times B)=(F, A) \otimes(G, B)$ and $H=F \times G$.

Definition 4.2 (see [23]) Let $\left(X, \tau_{1}, A_{1}\right)$ and $\left(Y, \tau_{2}, A_{2}\right)$ be two soft topological spaces. The soft topological space $\left(X \times Y, \tau, A_{1} \times A_{2}\right)$, where $\tau$ is the collection of all soft unions of elements of

$$
\left\{\left(F, A_{1}\right) \otimes\left(G, A_{2}\right):\left(F, A_{1}\right) \in \tau_{1},\left(G, A_{2}\right) \in \tau_{2}\right\},
$$

is called soft product topological space over $X \times Y$. Symbolically, we write $\tau=\tau_{1} \times \tau_{2}$.

Proposition 4.3 Let $\left(X, \tau_{1}, A_{1}\right)$ and $\left(Y, \tau_{2}, A_{2}\right)$ be two soft topological spaces, $e_{1}: A_{1} \times A_{2} \rightarrow A_{1}$, where

$$
e_{1}\left(a_{1}, a_{2}\right)=a_{1}
$$

for every $\left(a_{1}, a_{2}\right) \in A_{1} \times A_{2}$, and $e_{2}: A_{1} \times A_{2} \rightarrow A_{2}$, where

$$
e_{2}\left(a_{1}, a_{2}\right)=a_{2}
$$

for every $\left(a_{1}, a_{2}\right) \in A_{1} \times A_{2}$. The maps $p r_{1}: X \times Y \rightarrow X$ and $p r_{2}: X \times Y \rightarrow Y$, where $p r_{1}(x, y)=x$ and $p r_{2}(x, y)=y$, for every $(x, y) \in X \times Y$, are soft $e_{1}$-continuous and soft $e_{2}$ continuous, respectively.

Proof. We prove that the map $p r_{1}$ is soft $e_{1}$-continuous. By Proposition 2.18 it suffices to prove that $\Phi_{p r_{1} e_{1}}^{-1}\left(G, A_{1}\right) \in \tau_{1} \times \tau_{2}$, for every $\left(G, A_{1}\right) \in \tau_{1}$. Let $\left(G, A_{1}\right) \in \tau_{1}$. Then, $\Phi_{p r_{1} e_{1}}^{-1}\left(G, A_{1}\right)$ is the soft set

$$
\left(F, A_{1} \times A_{2}\right) \in \mathrm{SS}\left(X \times Y, A_{1} \times A_{2}\right)
$$

such that

$$
\begin{aligned}
F\left(a_{1}, a_{2}\right) & =p r_{1}^{-1}\left(G\left(e_{1}\left(a_{1}, a_{2}\right)\right)\right) \\
& =p r_{1}^{-1}\left(G\left(a_{1}\right)\right)=G\left(a_{1}\right) \times Y,
\end{aligned}
$$

for every $\left(a_{1}, a_{2}\right) \in A_{1} \times A_{2}$. Thus,

$$
\Phi_{p r_{1} e_{1}}^{-1}\left(G, A_{1}\right)=\left(F, A_{1} \times A_{2}\right)=\left(G, A_{1}\right) \times \mathbf{1}_{A_{2}} .
$$

Since $\left(G, A_{1}\right) \in \tau_{1}$ and $\mathbf{1}_{A_{2}} \in \tau_{2}$, we have

$$
\Phi_{p r_{1} e_{1}}^{-1}\left(G, A_{1}\right) \in \tau_{1} \times \tau_{2} .
$$

This means that the map $p r_{1}$ is soft $e_{1}$-continuous.

Similarly, we can prove that the map $p r_{2}$ is soft $e_{2}$ continuous.

Proposition 4.4 Let $\left(X, \tau_{1}, A_{1}\right),\left(Y, \tau_{2}, A_{2}\right)$ be two soft topological spaces, $\left(F, A_{1}\right) \in \operatorname{SS}\left(X, A_{1}\right)$, and $\left(G, A_{2}\right) \in \mathrm{SS}\left(Y, A_{2}\right)$. Then,

$$
\mathrm{Cl}\left(\left(F, A_{1}\right) \otimes\left(G, A_{2}\right)\right)=\mathrm{Cl}\left(F, A_{1}\right) \otimes \mathrm{Cl}\left(G, A_{2}\right) .
$$

Proof. By Proposition 2.14 we have:

(1) $\mathrm{Cl}\left(F, A_{1}\right)=\left(R_{F, A_{1}}, A_{1}\right)$, where the map $R_{F, A_{1}}: A_{1} \rightarrow$ $\mathscr{P}(X)$ defined as follows: $R_{F, A_{1}}\left(a_{1}\right)=\operatorname{cl}\left(F, a_{1}\right)$, for every $a_{1} \in A_{1}$. 
(2) $\mathrm{Cl}\left(G, A_{2}\right)=\left(R_{G, A_{2}}, A_{2}\right)$, where the map $R_{G, A_{2}}: A_{2} \rightarrow$ $\mathscr{P}(Y)$ defined as follows: $R_{G, A_{2}}\left(a_{2}\right)=\operatorname{cl}\left(G, a_{2}\right)$, for every $a_{2} \in A_{2}$.

(3) $\operatorname{Cl}\left(\left(F, A_{1}\right) \otimes\left(G, A_{2}\right)\right)=\left(R, A_{1} \times A_{2}\right)$, where the map

$$
R: A_{1} \times A_{2} \rightarrow \mathscr{P}(X \times Y)
$$

defined as follows:

$$
R\left(a_{1}, a_{2}\right)=\operatorname{cl}\left(F \times G,\left(a_{1}, a_{2}\right)\right),
$$

for every $\left(a_{1}, a_{2}\right) \in A_{1} \times A_{2}$. We observe that

$$
\operatorname{cl}\left(F \times G,\left(a_{1}, a_{2}\right)\right)=\operatorname{cl}\left(F, a_{1}\right) \times \operatorname{cl}\left(G, a_{2}\right) .
$$

Thus, for every $\left(a_{1}, a_{2}\right) \in A_{1} \times A_{2}$ we have $R\left(a_{1}, a_{2}\right)=R_{F, A_{1}}\left(a_{1}\right) \times R_{G, A_{2}}\left(a_{2}\right)$. This means that $\mathrm{Cl}\left(\left(F, A_{1}\right) \otimes\left(G, A_{2}\right)\right)=\mathrm{Cl}\left(F, A_{1}\right) \otimes \mathrm{Cl}\left(G, A_{2}\right)$.

Notation 4.5 Let $\left(X, \tau_{1}, A_{1}\right),\left(Y, \tau_{2}, A_{2}\right)$, and $\left(Z, \tau_{3}, A_{3}\right)$ be three soft topological spaces.

(1) If $x \in X, y \in Y$, and $f: X \times Y \rightarrow Z$, then by $f_{x}$ we denote the map of $Y$ into $Z$ defined by $f_{x}(y)=f(x, y)$ for every $y \in Y$. Also, by $f^{y}$ we denote the map of $X$ into $Z$ defined by $f^{y}(x)=f(x, y)$ for every $x \in X$.

(2) If $a_{1} \in A_{1}, a_{2} \in A_{2}$, and $e: A_{1} \times A_{2} \rightarrow A_{3}$, then by $e_{a_{1}}$ we denote the map of $A_{2}$ into $A_{3}$ defined by $e_{a_{1}}\left(a_{2}\right)=e\left(a_{1}, a_{2}\right)$ for every $a_{2} \in A_{2}$. Also, by $e^{a_{2}}$ we denote the map of $A_{1}$ into $A_{3}$ defined by $e^{a_{2}}\left(a_{1}\right)=e\left(a_{1}, a_{2}\right)$ for every $a_{1} \in A_{1}$.

Proposition 4.6 Let $\left(X, \tau_{1}, A_{1}\right),\left(Y, \tau_{2}, A_{2}\right)$, and $\left(Z, \tau_{3}, A_{3}\right)$ be three soft topological spaces, $e: A_{1} \times A_{2} \rightarrow A_{3}$, and $f$ : $X \times Y \rightarrow Z$ a soft $e$-continuous map. Then, the following statements are true:

(1) For every $x \in X$ and $a_{1} \in A_{1}$ the map $f_{x}: Y \rightarrow Z$ is soft $e_{a_{1}}$-continuous.

(2) For every $y \in Y$ and $a_{2} \in A_{2}$ the map $f^{y}: X \rightarrow Z$ is soft $e^{a_{2}}$-continuous.

Proof. We prove only the statement (1). Let $y \in Y, a_{2} \in A_{2}$, and $\left(G, A_{3}\right)$ be an $e_{a_{1}}\left(a_{2}\right)$-soft open neighborhood of $f_{x}(y)$ in $\left(Z, \tau_{3}, A_{3}\right)$. It suffices to prove that there exists an $a_{2}$-soft open neighborhood $\left(G_{2}, A_{2}\right)$ of $y$ in $\left(Y, \tau_{2}, A_{2}\right)$ such that

$$
\Phi_{f_{x} e_{a_{1}}}\left(G_{2}, A_{2}\right) \sqsubseteq\left(G, A_{3}\right) .
$$

Since the map $f: X \times Y \rightarrow Z$ is soft $e$-continuous at the point $(x, y)$, by Proposition 2.19 and Definition 4.2, there exist an $a_{1}$-soft open neighborhood $\left(G_{1}, A_{1}\right)$ of $x$ in $\left(X, \tau_{1}, A_{1}\right)$ and an $a_{2}$-soft open neighborhood $\left(G_{2}, A_{2}\right)$ of $y$ in $\left(Y, \tau_{2}, A_{2}\right)$ such that

$$
\Phi_{f e}\left(\left(G_{1}, A_{1}\right) \otimes\left(G_{2}, A_{2}\right)\right) \sqsubseteq\left(G, A_{3}\right) .
$$

Let

$$
\Phi_{f_{x} e_{a_{1}}}\left(G_{2}, A_{2}\right)=\left(H, A_{3}\right)
$$

and

$$
\Phi_{f e}\left(\left(G_{1}, A_{1}\right) \otimes\left(G_{2}, A_{2}\right)\right)=\left(H^{\prime}, A_{3}\right) .
$$

Then, for every $a_{3} \in A_{3}$ we have

$$
H\left(a_{3}\right)=\left\{\begin{array}{l}
\bigcup\left\{f_{x}\left(G_{2}(b)\right): b \in e_{a_{1}}^{-1}\left(\left\{a_{3}\right\}\right)\right\} \\
\text { if } e_{a_{1}}^{-1}\left(\left\{a_{3}\right\}\right) \neq \emptyset \\
\emptyset, \text { if } e_{a_{1}}^{-1}\left(\left\{a_{3}\right\}\right)=\emptyset
\end{array}\right.
$$

and

$$
H^{\prime}\left(a_{3}\right)=\left\{\begin{array}{l}
\bigcup\left\{f\left(G_{1}(a) \times G_{2}(b)\right):(a, b) \in e^{-1}\left(\left\{a_{3}\right\}\right)\right\}, \\
\text { if } e^{-1}\left(\left\{a_{3}\right\}\right) \neq \emptyset, \\
\emptyset, \text { if } e^{-1}\left(\left\{a_{3}\right\}\right)=\emptyset .
\end{array}\right.
$$

Let $a_{3} \in A_{3}$. We prove that

$$
H\left(a_{3}\right) \subseteq G\left(a_{3}\right) .
$$

If $e_{a_{1}}^{-1}\left(\left\{a_{3}\right\}\right)=\emptyset$, then $H\left(a_{3}\right)=\emptyset \subseteq G\left(a_{3}\right)$. We suppose that $e_{a_{1}}^{-1}\left(\left\{a_{3}\right\}\right) \neq \emptyset$ and $b \in e_{a_{1}}^{-1}\left(\left\{a_{3}\right\}\right)$. Then, $\left(a_{1}, b\right) \in e^{-1}\left(\left\{a_{3}\right\}\right)$. It suffices to prove that

$$
f_{x}\left(G_{2}(b)\right) \subseteq G\left(a_{3}\right) .
$$

Indeed, we have

$$
f_{x}\left(G_{2}(b)\right)=\left\{f(x, y): y \in G_{2}(b)\right\},
$$

$x \in G_{1}\left(a_{1}\right)$, and $f\left(G_{1}\left(a_{1}\right) \times G_{2}(b)\right) \subseteq H^{\prime}\left(a_{3}\right) \subseteq G\left(a_{3}\right)$. Therefore, for every $y \in G_{2}(b)$ we have

$$
f(x, y) \in f\left(G_{1}\left(a_{1}\right) \times G_{2}(b)\right) \subseteq G\left(a_{3}\right) .
$$

This means that

$$
H\left(a_{3}\right)=\bigcup\left\{f_{x}\left(G_{2}(b)\right): b \in e_{a_{1}}^{-1}\left(\left\{a_{3}\right\}\right)\right\} \subseteq G\left(a_{3}\right),
$$

for every $a_{3} \in A_{3}$. Thus,

$$
\Phi_{f_{x} e_{a_{1}}}\left(G_{2}, A_{2}\right)=\left(H, A_{3}\right) \sqsubseteq\left(G, A_{3}\right) .
$$

\section{Soft $\theta$-topology: $\theta$-open, $\theta$-closed soft sets and soft $\theta$-continuity}

Definition 5.1 Let $(X, \tau, A)$ be a soft topological space and $a \in A$. A point $x \in X$ is said to be an $a$ - $\theta$-interior point of $(F, A) \in \mathrm{SS}(X, A)$ if there exists an $a$-soft open neighborhood $(G, A)$ of $x$ such that $\mathrm{Cl}(G, A) \sqsubseteq(F, A)$. The set of all $a$ - $\theta$-interior points of $(F, A)$ is denoted by $\operatorname{int}_{\theta}(F, a)$.

We observe that $\operatorname{int}_{\theta}(F, p) \subseteq F(p)$, for every $p \in A$.

Definition 5.2 Let $(X, \tau, A)$ be a soft topological space and $(F, A) \in \operatorname{SS}(X, A)$. The $\theta$-interior $\operatorname{Int}_{\theta}(F, A)$ of $(F, A)$ is the soft set $\left(R_{F, A}, A\right)$, where the map $R_{F, A}: A \rightarrow \mathscr{P}(X)$ defined as follows: $R_{F, A}(p)=\operatorname{int}_{\theta}(F, p)$, for every $p \in A$.

We observe that $\operatorname{Int}_{\theta}(F, A) \sqsubseteq(F, A)$. 
Definition 5.3 (1) Let $\left(F_{i}, A\right) \in \mathrm{SS}(X, A), i \in I$. Then, by $\cap\left\{F_{i}: i \in I\right\}$ and $\cup\left\{F_{i}: i \in I\right\}$ we denote the maps from $A$ to $\mathscr{P}(X)$ for which

$$
\cap\left\{F_{i}: i \in I\right\}(p)=\cap\left\{F_{i}(p): i \in I\right\}
$$

and

$$
\cup\left\{F_{i}: i \in I\right\}(p)=\cup\left\{F_{i}(p): i \in I\right\},
$$

for every $p \in A$.

(2) Let $(F, A) \in \mathrm{SS}(X, A)$. Then by $F^{c}$ we denote the map from $A$ to $\mathscr{P}(X)$ for which $F^{c}(p)=X \backslash F(p)$, for every $p \in A$. Obviously, $(F, A)^{c}=\left(F^{c}, A\right)$.

Remark. We observe that for the soft sets

$$
\left(\cap\left\{F_{i}: i \in I\right\}, A\right) \text { and }\left(\cup\left\{F_{i}: i \in I\right\}, A\right)
$$

of Definition 5.3(1) we have the following properties:

(i) $\left(\cap\left\{F_{i}: i \in I\right\}, A\right)=\sqcap\left\{\left(F_{i}, A\right): i \in I\right\}$.

(ii) $\left(\cup\left\{F_{i}: i \in I\right\}, A\right)=\sqcup\left\{\left(F_{i}, A\right): i \in I\right\}$.

(iii) If $(G, A) \in \mathrm{SS}(X, A)$, then

$$
\left(\cap\left\{F_{i}: i \in I\right\}, A\right) \sqcup(G, A)=\left(\cap\left\{F_{i} \cup G: i \in I\right\}, A\right) .
$$

(iv) If $(G, A) \in \mathrm{SS}(X, A)$, then

$$
\left(\cup\left\{F_{i}: i \in I\right\}, A\right) \sqcap(G, A)=\left(\cup\left\{F_{i} \cap G: i \in I\right\}, A\right) .
$$

Proposition 5.4 The following statements are true: (1) If $\left(F_{1}, A\right),\left(F_{2}, A\right) \in \operatorname{SS}(X, A)$ and $p \in A$, then

$$
\operatorname{int}_{\theta}\left(F_{1}, p\right) \cap \operatorname{int}_{\theta}\left(F_{2}, p\right)=\operatorname{int}_{\theta}\left(F_{1} \cap F_{2}, p\right) .
$$

(2) If $\left(F_{i}, A\right) \in \operatorname{SS}(X, A), i \in I$ and $p \in A$, then

$$
\cup\left\{\operatorname{int}_{\theta}\left(F_{i}, p\right): i \in I\right\} \subseteq \operatorname{int}_{\theta}\left(\cup\left\{F_{i}: i \in I\right\}, p\right) .
$$

Proof. (1) We prove that

$$
\operatorname{int}_{\theta}\left(F_{1}, p\right) \cap \operatorname{int}_{\theta}\left(F_{2}, p\right) \subseteq \operatorname{int}_{\theta}\left(F_{1} \cap F_{2}, p\right) .
$$

Let $x \in \operatorname{int}_{\theta}\left(F_{1}, p\right) \cap \operatorname{int}_{\theta}\left(F_{2}, p\right)$. Then, there exist two $p$ soft open neighborhoods $\left(G_{1}, A\right)$ and $\left(G_{2}, A\right)$ of $x$ such that $\mathrm{Cl}\left(G_{1}, A\right) \sqsubseteq\left(F_{1}, A\right)$ and $\mathrm{Cl}\left(G_{2}, A\right) \sqsubseteq\left(F_{2}, A\right)$. The soft set $\left(G_{1}, A\right) \sqcap\left(G_{2}, A\right)$ is a $p$-soft open neighborhood of $x$ and

$$
\begin{aligned}
\mathrm{Cl}\left(\left(G_{1}, A\right) \sqcap\left(G_{2}, A\right)\right) & \sqsubseteq \mathrm{Cl}\left(G_{1}, A\right) \sqcap \mathrm{Cl}\left(G_{2}, A\right) \\
& \sqsubseteq\left(F_{1}, A\right) \sqcap\left(F_{2}, A\right) \\
& =\left(F_{1} \cap F_{2}, A\right) .
\end{aligned}
$$

Thus, $x \in \operatorname{int}_{\theta}\left(F_{1} \cap F_{2}, p\right)$.

Conversely, we prove that

$$
\operatorname{int}_{\theta}\left(F_{1} \cap F_{2}, p\right) \subseteq \operatorname{int}_{\theta}\left(F_{1}, p\right) \cap \operatorname{int}_{\theta}\left(F_{2}, p\right) .
$$

Let $x \in \operatorname{int}_{\theta}\left(F_{1} \cap F_{2}, p\right)$. Then, there exists a $p$-soft open neighborhood $(G, A)$ of $x$ such that

$$
\mathrm{Cl}(G, A) \sqsubseteq\left(F_{1} \cap F_{2}, A\right) .
$$

Therefore, $\operatorname{Cl}(G, A) \sqsubseteq\left(F_{1}, A\right)$ and $\mathrm{Cl}(G, A) \sqsubseteq\left(F_{2}, A\right)$. Thus, $x \in \operatorname{int}_{\theta}\left(F_{1}, p\right) \cap \operatorname{int}_{\theta}\left(F_{2}, p\right)$.

(2) Let $x \in \cup\left\{\operatorname{int}_{\theta}\left(F_{i}, p\right): i \in I\right\}$. Then, there exists $i \in I$ such that $x \in \operatorname{int}_{\theta}\left(F_{i}, p\right)$. Therefore, there exists a $p$-soft open neighborhood $\left(G_{i}, A\right)$ of $x$ such that

$$
\mathrm{Cl}\left(G_{i}, A\right) \sqsubseteq\left(F_{i}, A\right) \sqsubseteq\left(\cup\left\{F_{i}: i \in I\right\}, A\right) .
$$

Thus, $x \in \operatorname{int}_{\theta}\left(\cup\left\{F_{i}: i \in I\right\}, p\right)$.

Corollary 5.5 The following statements are true:

(1) $\operatorname{Int}_{\theta}\left(F_{1}, A\right) \sqcap \operatorname{Int}_{\theta}\left(F_{2}, A\right)=\operatorname{Int}_{\theta}\left(F_{1} \cap F_{2}, A\right)$.

(2) $\sqcup\left\{\operatorname{Int}_{\theta}\left(F_{i}, A\right): i \in I\right\} \sqsubseteq \operatorname{Int}_{\theta}\left(\cup\left\{F_{i}: i \in I\right\}, A\right)$.

Definition 5.6 A soft set $(F, A)$ is said to be $\theta$-open if $\operatorname{Int}_{\theta}(F, A)=(F, A)$.

We observe that a soft set $(F, A)$ is $\theta$-open if and only if $\operatorname{int}_{\theta}(F, p)=F(p)$, for every $p \in A$.

Proposition 5.7 The family $\tau_{\theta}$ of all $\theta$-open soft sets defines a soft topology on $X$.

Proof. (1) We have $\mathbf{0}_{A}, \mathbf{1}_{A} \in \tau_{\theta}$. Indeed, we observe that $\operatorname{Int}_{\theta}\left(\mathbf{0}_{A}\right)=\mathbf{0}_{A}$ and $\operatorname{Int}_{\theta}\left(\mathbf{1}_{A}\right)=\mathbf{1}_{A}$.

(2) Let $(G, A),(H, A) \in \tau_{\theta}$. We prove that $(G, A) \sqcap(H, A) \in \tau_{\theta}$. It suffices to prove that $(G \cap H, A) \in \tau_{\theta}$. Indeed, $\operatorname{Int}_{\theta}(G, A)=(G, A)$ and $\operatorname{Int}_{\theta}(H, A)=(H, A)$. By Corollary 5.5(1) we have

$$
\begin{aligned}
(G \cap H, A) & =(G, A) \sqcap(H, A) \\
& =\operatorname{Int}_{\theta}(G, A) \sqcap \operatorname{Int}_{\theta}(H, A) \\
& =\operatorname{Int}_{\theta}(G \cap H, A) .
\end{aligned}
$$

(3) Let $\left(G_{i}, A\right) \in \tau_{\theta}$ for every $i \in I$. We prove that $\sqcup\left\{\left(G_{i}, A\right): i \in I\right\} \in \tau_{\theta}$. It suffices to prove that $\left(\cup\left\{G_{i}: i \in I\right\}, A\right) \in \tau_{\theta}$, that is

$$
\operatorname{Int}_{\theta}\left(\cup\left\{G_{i}: i \in I\right\}, A\right)=\left(\cup\left\{G_{i}: i \in I\right\}, A\right) .
$$

Indeed, for every $i \in I$ we have $\operatorname{Int}_{\theta}\left(G_{i}, A\right)=\left(G_{i}, A\right)$. By Corollary 5.5(2) we have

$$
\begin{aligned}
\left(\cup\left\{G_{i}: i \in I\right\}, A\right) & =\sqcup\left\{\left(G_{i}, A\right): i \in I\right\} \\
& =\sqcup\left\{\operatorname{Int}_{\theta}\left(G_{i}, A\right): i \in I\right\} \\
& \sqsubseteq \operatorname{Int}_{\theta}\left(\cup\left\{G_{i}: i \in I\right\}, A\right) .
\end{aligned}
$$

Also,

$$
\operatorname{Int}_{\theta}\left(\cup\left\{G_{i}: i \in I\right\}, A\right) \sqsubseteq\left(\cup\left\{G_{i}: i \in I\right\}, A\right) .
$$

Therefore, $\operatorname{Int}_{\theta}\left(\cup\left\{G_{i}: i \in I\right\}, A\right)=\left(\cup\left\{G_{i}: i \in I\right\}, A\right)$.

Proposition 5.8 The following statements are true:

(1) $\tau_{\theta} \subseteq \tau$

(2) $\tau \supseteq \tau_{\theta} \supseteq\left(\tau_{\theta}\right)_{\theta} \supseteq\left(\left(\tau_{\theta}\right)_{\theta}\right)_{\theta} \supseteq \ldots$

(3) $\operatorname{Int}_{\theta}(F, A) \in \tau$, for every $(F, A) \in \mathrm{SS}(X, A)$.

(4) $\operatorname{Int}_{\theta}(F, A)=\sqcup\{(G, A) \in \tau: \mathrm{Cl}(G, A) \sqsubseteq(F, A)\}$, for every $(F, A) \in \mathrm{SS}(X, A)$.

Proof. (1) Let $(G, A) \in \tau_{\theta}$. Then, $\operatorname{Int}_{\theta}(G, A)=(G, A)$. We prove that $(G, A) \in \tau$. By Proposition 2.11 it suffices to prove that for every $a \in A$ and $x \in G(a)$ there exists an 
$a$-soft open neighborhood $\left(G_{(a, x)}, A\right)$ of $x$ in $(X, \tau, A)$ such that $\left(G_{(a, x)}, A\right) \sqsubseteq(G, A)$. Let $a \in A$ and $x \in G(a)$. Then, $x \in \operatorname{int}_{\theta}(G, a)$. Therefore, there exists an $a$-soft open neighborhood $\left(G_{(a, x)}, A\right)$ of $x$ such that $\mathrm{Cl}\left(G_{(a, x)}, A\right) \sqsubseteq(G, A)$. Thus, $\left(G_{(a, x)}, A\right) \sqsubseteq(G, A)$.

(2) Follows by (1) and Proposition 5.7.

(3) Let $(F, A) \in \mathrm{SS}(X, A)$. We prove that $\operatorname{Int}_{\theta}(F, A) \in \tau$. By Proposition 2.11 it suffices to prove that for every $a \in A$ and $x \in \operatorname{int}_{\theta}(F, a)$ there exists an $a$-soft open neighborhood $\left(G_{(a, x)}, A\right)$ of $x$ in $(X, \tau, A)$ such that

$$
\left(G_{(a, x)}, A\right) \sqsubseteq \operatorname{Int}_{\theta}(F, A) .
$$

Let $a \in A$ and $x \in \operatorname{int}_{\theta}(F, a)$. Then, there exists an $a$-soft open neighborhood $\left(G_{(a, x)}, A\right)$ of $x$ such that

$$
\mathrm{Cl}\left(G_{(a, x)}, A\right) \sqsubseteq(F, A) .
$$

Obviously, $G_{(a, x)}(p) \subseteq \operatorname{int}_{\theta}(F, p)$, for every $p \in A$. Thus, $\left(G_{(a, x)}, A\right) \sqsubseteq \operatorname{Int}_{\theta}(F, A)$.

(4) Follows by (3) and Definitions 5.1 and 5.2

Remark. In general, $\operatorname{Int}_{\theta}(F, A) \notin \tau_{\theta}$.

Example 5.9 (1) Let $(X, \tau, A)$ be the soft topological space of Example 3.7(2). Then, $\tau_{\theta}=\left\{\mathbf{0}_{A}, \mathbf{1}_{A}\right\} \neq \tau$.

(2) Let $(X, \tau, A)$ be the soft topological space of Example 3.9. We consider the soft set $(F, A)$ over $X$ defined as follows:

$$
F(p)=\left\{\begin{array}{l}
\{x, z\}, \text { if } a=0, \\
\{x, y\}, \text { if } a=1 .
\end{array}\right.
$$

Then, $\operatorname{Int}_{\theta}(F, A)=(G, A) \in \tau$. Since $(G, A) \neq(F, A)$, we have $\operatorname{Int}_{\theta}(F, A) \notin \tau_{\theta}$.

Definition 5.10 Let $(X, \tau, A)$ be a soft topological space and $a \in A$. A point $x \in X$ is said to be an $a$ - $\theta$-cluster point of $(F, A) \in \mathrm{SS}(X, A)$ if for every $a$-soft open neighborhood $(G, A)$ of $x$ we have $(F, A) \sqcap \mathrm{Cl}(G, A) \neq \mathbf{0}_{A}$. The set of all $a$ - $\theta$-cluster points of $(F, A)$ is denoted by $\operatorname{cl}_{\theta}(F, a)$.

We observe that $F(p) \subseteq \operatorname{cl}_{\theta}(F, p)$, for every $p \in A$.

Definition 5.11 Let $(X, \tau, A)$ be a soft topological space and $(F, A) \in \mathrm{SS}(X, A)$. The $\theta$-closure of $(F, A)$ is the soft set $\mathrm{Cl}_{\theta}(F, A)=\left(R_{F, A}, A\right)$, where the map $R_{F, A}: A \rightarrow \mathscr{P}(X)$ defined as follows: $R_{F, A}(p)=\operatorname{cl}_{\theta}(F, p)$, for every $p \in A$.

We observe that $(F, A) \sqsubseteq \mathrm{Cl}_{\theta}(F, A)$ and $\mathrm{Cl}(F, A) \sqsubseteq \mathrm{Cl}_{\theta}(F, A)$.

Definition 5.12 A soft set $(F, A)$ is said to be $\theta$-closed if $\mathrm{Cl}_{\theta}(F, A)=(F, A)$. The family of all $\theta$-closed soft sets is denoted by $\tau_{\theta}^{c}$.

We observe that a soft set $(F, A)$ is $\theta$-closed if and only if $\operatorname{cl}_{\theta}(F, p)=F(p)$, for every $p \in A$.

The proof of the following proposition is straightforward verification of the Proposition 5.7 and Propositions 2.10 and 2.12 of [9].
Proposition 5.13 Let $(X, \tau, A)$ be a soft topological space. The family $\tau_{\theta}^{c}$ has the following properties:

(1) $\mathbf{0}_{A}, \mathbf{1}_{A} \in \tau_{\theta}^{c}$.

(2) If $(Q, A),(R, A) \in \tau_{\theta}^{c}$, then $(Q, A) \sqcup(R, A) \in \tau_{\theta}^{c}$.

(3) If $\left(Q_{i}, A\right) \in \tau_{\theta}^{c}$ for every $i \in I$, then

$$
\sqcap\left\{\left(Q_{i}, A\right): i \in I\right\} \in \tau_{\theta}^{c} .
$$

Proposition 5.14 The following statements are true:

(1) If $\left(F_{1}, A\right),\left(F_{2}, A\right) \in \mathrm{SS}(X, A)$ and $p \in A$, then

$$
\operatorname{cl}_{\theta}\left(F_{1}, p\right) \cup \operatorname{cl}_{\theta}\left(F_{2}, p\right)=\operatorname{cl}_{\theta}\left(F_{1} \cup F_{2}, p\right) .
$$

(2) If $\left(F_{i}, A\right) \in \mathrm{SS}(X, A), i \in I$ and $p \in A$, then

$$
\operatorname{cl}_{\theta}\left(\cap\left\{F_{i}: i \in I\right\}, p\right) \subseteq \cap\left\{\operatorname{cl}_{\theta}\left(F_{i}, p\right): i \in I\right\} .
$$

Proof. (1) We prove that

$$
\operatorname{cl}_{\theta}\left(F_{1}, p\right) \cup \operatorname{cl}_{\theta}\left(F_{2}, p\right) \subseteq \operatorname{cl}_{\theta}\left(F_{1} \cup F_{2}, p\right) .
$$

Let $x \in \operatorname{cl}_{\theta}\left(F_{1}, p\right) \cup \operatorname{cl}_{\theta}\left(F_{2}, p\right)$ and $(G, A)$ be a $p$-soft open neighborhood of $x$. We must prove that $\left(F_{1} \cup F_{2}, A\right) \sqcap \mathrm{Cl}(G, A) \neq \mathbf{0}_{A}$. Without loss of generality we suppose that $x \in \operatorname{cl}_{\theta}\left(F_{1}, p\right)$. Then, $\left(F_{1}, A\right) \sqcap \mathrm{Cl}(G, A) \neq \mathbf{0}_{A}$. Therefore,

$$
\left(F_{1} \cup F_{2}, A\right) \sqcap \mathrm{Cl}(G, A) \neq \mathbf{0}_{A} .
$$

Thus, $x \in \operatorname{cl}_{\theta}\left(F_{1} \cup F_{2}, p\right)$.

Conversely, we prove that

$$
\operatorname{cl}_{\theta}\left(F_{1} \cup F_{2}, p\right) \subseteq \operatorname{cl}_{\theta}\left(F_{1}, p\right) \cup \operatorname{cl}_{\theta}\left(F_{2}, p\right) .
$$

Let $x \in \operatorname{cl}_{\theta}\left(F_{1} \cup F_{2}, p\right)$ and $(G, A)$ be a $p$-soft open neighborhood of $x$. Then,

$$
\left(F_{1} \cup F_{2}, A\right) \sqcap \mathrm{Cl}(G, A) \neq \mathbf{0}_{A} .
$$

Therefore,

$$
\left(F_{1}, A\right) \sqcap \mathrm{Cl}(G, A) \neq \mathbf{0}_{A}
$$

or

$$
\left(F_{2}, A\right) \sqcap \mathrm{Cl}(G, A) \neq \mathbf{0}_{A} .
$$

Thus, $x \in \operatorname{cl}_{\theta}\left(F_{1}, p\right) \cup \operatorname{cl}_{\theta}\left(F_{2}, p\right)$.

(2) Let $x \in \operatorname{cl}_{\theta}\left(\cap\left\{F_{i}: i \in I\right\}, p\right)$ and $(G, A)$ be a $p$-soft open neighborhood of $x$. Then, $\left(\cap\left\{F_{i}: i \in I\right\}, A\right) \sqcap \mathrm{Cl}(G, A) \neq \mathbf{0}_{A}$. Therefore, $\left(F_{i}, A\right) \sqcap \mathrm{Cl}(G, A) \neq \mathbf{0}_{A}$, for every $i \in I$. Thus, $x \in \cap\left\{\operatorname{cl}_{\theta}\left(F_{i}, p\right): i \in I\right\}$.

Corollary 5.15 The following statements are true:

(1) $\mathrm{Cl}_{\theta}\left(F_{1}, A\right) \sqcup \mathrm{Cl}_{\theta}\left(F_{2}, A\right)=\mathrm{Cl}_{\theta}\left(F_{1} \cup F_{2}, A\right)$.

(2) $\mathrm{Cl}_{\theta}\left(\cap\left\{F_{i}: i \in I\right\}, A\right) \sqsubseteq \sqcap\left\{\mathrm{Cl}_{\theta}\left(F_{i}, A\right): i \in I\right\}$.

Proposition 5.16 Let $(X, \tau, A)$ be a soft space, $p \in A$, and $(F, A) \in \mathrm{SS}(X, A)$. Then, $\operatorname{cl}_{\theta}\left(F^{c}, p\right)=X \backslash \operatorname{int}_{\theta}(F, p)$.

Proof. We prove that $\operatorname{cl}_{\theta}\left(F^{c}, p\right) \subseteq X \backslash \operatorname{int}_{\theta}(F, p)$. Let $x \in \operatorname{cl}_{\theta}\left(F^{c}, p\right)$. Then, for every $p$-soft open neighborhood $(G, A)$ of $x$ we have $(F, A)^{c} \sqcap \mathrm{Cl}(G, A) \neq \mathbf{0}_{A}$. We suppose 
that $x \in \operatorname{int}_{\theta}(F, p)$. Then, there exists a $p$-soft open neighborhood $(G, A)$ of $x$ such that $\mathrm{Cl}(G, A) \sqsubseteq(F, A)$. Therefore, $\quad(F, A)^{c} \sqcap \mathrm{Cl}(G, A)=\mathbf{0}_{A}$, which is a contradiction. Thus, $x \in X \backslash \operatorname{int}_{\theta}(F, p)$.

Conversely, we prove that $X \backslash \operatorname{int}_{\theta}(F, p) \subseteq \operatorname{cl}_{\theta}\left(F^{c}, p\right)$. Let $x \in X \backslash \operatorname{int}_{\theta}(F, p)$ and $(G, A)$ be a $p$-soft open neighborhood of $x$. We must prove that

$$
(F, A)^{c} \sqcap \mathrm{Cl}(G, A) \neq \mathbf{0}_{A} .
$$

Since $x \notin \operatorname{int}_{\theta}(F, p)$, the relation $\operatorname{Cl}(G, A) \sqsubseteq(F, A)$ is not true. Therefore, there exists $p_{1} \in A$ such that

$$
\mathrm{cl}\left(G, p_{1}\right) \nsubseteq F\left(p_{1}\right) \text {. }
$$

This means that $\left(X \backslash F\left(p_{1}\right)\right) \cap \operatorname{cl}\left(G, p_{1}\right) \neq \emptyset$ and, therefore,

$$
(F, A)^{c} \sqcap \mathrm{Cl}(G, A) \neq \mathbf{0}_{A} .
$$

Thus, $x \in \operatorname{cl}_{\theta}\left(F^{c}, p\right)$.

Corollary 5.17 Let $(X, \tau, A)$ be a soft topological space and $(F, A) \in \mathrm{SS}(X, A)$. Then, the following statements are true:

(1) $\mathrm{Cl}_{\theta}\left((F, A)^{c}\right)=\mathrm{Cl}_{\theta}\left(F^{c}, A\right)=\left(\operatorname{Int}_{\theta}(F, A)\right)^{c}$.

(2) The soft set $(F, A)$ is $\theta$-open if and only if the soft set $(F, A)^{c}$ is $\theta$-closed.

By Proposition 5.8 and Corollary 5.17 we have the following proposition.

Proposition 5.18 The following statements are true:
(1) $\tau_{\theta}^{c} \subseteq \tau^{c}$.
(2) $\tau^{c} \supseteq \tau_{\theta}^{c} \supseteq\left(\tau_{\theta}^{c}\right)_{\theta}^{c} \supseteq\left(\left(\tau_{\theta}^{c}\right)_{\theta}^{c}\right)_{\theta}^{c} \supseteq \ldots$
(3) $\mathrm{Cl}_{\theta}(F, A) \in \tau^{c}$, for every $(F, A) \in \mathrm{SS}(X, A)$.

Remark. In general, $\mathrm{Cl}_{\theta}(F, A) \notin \tau_{\theta}^{c}$.

Example 5.19 Let $(X, \tau, A)$ be the soft topological space of Example 3.9. We consider the soft set $(F, A)$ over $X$ defined as follows:

$$
F(a)=\left\{\begin{array}{l}
\{x\}, \text { if } a=0 \\
\{y\}, \text { if } a=1
\end{array}\right.
$$

Then, $\mathrm{Cl}_{\theta}(F, A)=(G, A) \in \tau^{c}$. Since $(G, A) \neq(F, A)$, we have $\mathrm{Cl}_{\theta}(F, A) \notin \tau_{\theta}^{c}$.

Definition 5.20 Let $(X, \tau, A)$ be a soft topological space and $(F, A) \in \operatorname{SS}(X, A)$. The $\theta$-boundary of $(F, A)$ is the soft set $\operatorname{Bd}_{\theta}(F, A)=\left(R_{F, A}, A\right)$, where the map $R_{F, A}: A \rightarrow \mathscr{P}(X)$ defined as follows: $R_{F, A}(p)=\operatorname{cl}_{\theta}(F, p) \cap \operatorname{cl}_{\theta}\left(F^{c}, p\right)$, for every $p \in A$.

Proposition 5.21 Let $(X, \tau, A)$ be a soft topological space and $(F, A) \in \mathrm{SS}(X, A)$. Then, the following statements are true:

(1) $\operatorname{Bd}_{\theta}(F, A)=\mathrm{Cl}_{\theta}(F, A) \sqcap \mathrm{Cl}_{\theta}\left(F^{c}, A\right)$.

(2) $\operatorname{Bd}_{\theta}(F, A) \in \tau^{c}$.

(3) $\operatorname{Bd}_{\theta}(F, A)=\mathrm{Cl}_{\theta}(F, A) \sqcap\left(\operatorname{Int}_{\theta}(F, A)\right)^{c}$.

(4) $\mathrm{Cl}_{\theta}(F, A)=\operatorname{Int}_{\theta}(F, A) \sqcup \mathrm{Bd}_{\theta}(F, A)$.

(5) $\operatorname{Bd}_{\theta}(F, A)=\operatorname{Bd}_{\theta}\left(F^{c}, A\right)$.
Proof. (1) Is straightforward verification of the Definition 5.20 .

(2) Follows by relation (1) and Propositions 5.13 and 5.18(3).

(3) Follows by relation (1) and Corollary 5.17(1).

(4) We have

$\operatorname{Int}_{\theta}(F, A) \sqcup \mathrm{Bd}_{\theta}(F, A)=$

$\operatorname{Int}_{\theta}(F, A) \sqcup\left(\mathrm{Cl}_{\theta}(F, A) \sqcap \mathrm{Cl}_{\theta}\left(F^{c}, A\right)\right)=$

$\left(\operatorname{Int}_{\theta}(F, A) \sqcup \mathrm{Cl}_{\theta}(F, A)\right) \sqcap\left(\operatorname{Int}_{\theta}(F, A) \sqcup \mathrm{Cl}_{\theta}\left(F^{c}, A\right)\right)=$

$\mathrm{Cl}_{\theta}(F, A) \sqcap\left(\left(\mathrm{Cl}_{\theta}\left(F^{c}, A\right)\right)^{c} \sqcup \mathrm{Cl}_{\theta}\left(F^{c}, A\right)\right)=$

$\mathrm{Cl}_{\theta}(F, A) \sqcap \mathbf{1}_{A}=\mathrm{Cl}_{\theta}(F, A)$.

(5) Is straightforward verification of the Definition 5.20.

Definition 5.22 Let $(X, \tau, A)$ be a soft topological space, $a \in A$, and $x \in X$. We say that a soft set $(F, A)$ is an $a-\theta$ soft open neighborhood of $x$ in $(X, \tau, A)$ if $x \in F(a)$ and $(F, A) \in \tau_{\theta}$.

Proposition 5.23 Let $(X, \tau, A)$ be a soft topological space. Then, $(G, A) \in \tau_{\theta}$ if and only if for every $p \in A$ and $x \in$ $G(p)$ there exists a $p$ - $\theta$-soft open neighborhood $\left(G_{(p, x)}, A\right)$ of $x$ in $(X, \tau, A)$ such that $\left(G_{(p, x)}, A\right) \sqsubseteq(G, A)$.

Proof. Let $(G, A) \in \tau_{\theta}$. Then, for every $p \in A$ and $x \in G(p)$ we consider the soft set $\left(G_{(p, x)}, A\right)$, where $G_{(p, x)}=G$. Obviously, $\left(G_{(p, x)}, A\right)$ is a $p$ - $\theta$-soft open neighborhood of $x$.

Conversely, we suppose that for every $p \in A$ and $x \in$ $G(p)$ there exists a $p$ - $\theta$-soft open neighborhood $\left(G_{(p, x)}, A\right)$ of $x$ in $(X, \tau, A)$ such that $\left(G_{(p, x)}, A\right) \sqsubseteq(G, A)$. We prove that $(G, A) \in \tau_{\theta}$. We consider the set

$$
I=\{(p, x): p \in A, x \in G(p)\} .
$$

Then,

$$
(G, A)=\sqcup\left\{\left(G_{(p, x)}, A\right):(p, x) \in I\right\} .
$$

Also, for every $p \in A$ and $x \in G(p)$ we have

$$
\operatorname{Int}_{\theta}\left(G_{(p, x)}, A\right)=\left(G_{(p, x)}, A\right) .
$$

Thus, by Corollary 5.5(2) we have

$$
\begin{aligned}
(G, A) & =\sqcup\left\{\left(G_{(p, x)}, A\right):(p, x) \in I\right\} \\
& =\sqcup\left\{\operatorname{Int}_{\theta}\left(G_{(p, x)}, A\right):(p, x) \in I\right\} \\
& \sqsubseteq \operatorname{Int}_{\theta}\left(\cup\left\{G_{(p, x)}:(p, x) \in I\right\}, A\right)=\operatorname{Int}_{\theta}(G, A) .
\end{aligned}
$$

Also, $\operatorname{Int}_{\theta}(G, A) \sqsubseteq(G, A)$. This means that $\operatorname{Int}_{\theta}(G, A)=$ $(G, A)$ and, therefore, $(G, A) \in \tau_{\theta}$.

Proposition 5.24 Let $(X, \tau, A)$ be a soft topological space. Then, $(G, A) \in \tau_{\theta}$ if and only if for every $p \in A$ and $x \in$ $G(p)$ there exists a $p$-soft open neighborhood $\left(G_{(p, x)}, A\right)$ of $x$ such that $\mathrm{Cl}\left(G_{(p, x)}, A\right) \sqsubseteq(G, A)$.

Proof. Let $(G, A) \in \tau_{\theta}, p \in A$, and $x \in G(p)$. Then, $(G, A)=\operatorname{Int}_{\theta}(G, A)$ and, therefore,

$$
x \in G(p)=\operatorname{int}_{\theta}(G, p) .
$$

Thus, there exists a $p$-soft open neighborhood $\left(G_{(p, x)}, A\right)$ of $x$ such that $\mathrm{Cl}\left(G_{(p, x)}, A\right) \sqsubseteq(G, A)$. 
Conversely, we suppose that for every $p \in A$ and $x \in G(p)$ there exists a $p$-soft open neighborhood $\left(G_{(p, x)}, A\right)$ of $x$ such that $\mathrm{Cl}\left(G_{(p, x)}, A\right) \sqsubseteq(G, A)$. We prove that $(G, A) \in \tau_{\theta}$. It suffices to prove that $\operatorname{Int}_{\theta}(G, A)=(G, A)$ or equivalently, $\operatorname{int}_{\theta}(G, p)=G(p)$, for every $p \in A$. Let $p \in A$ and $x \in G(p)$. Then, $\mathrm{Cl}\left(G_{(p, x)}, A\right) \sqsubseteq(G, A)$ and, therefore, $x \in \operatorname{int}_{\theta}(G, p)$. Thus, $G(p) \subseteq \operatorname{int}_{\theta}(G, p)$. Also, $\operatorname{int}_{\theta}(G, p) \subseteq G(p)$. This means that $\operatorname{int}_{\theta}(G, p)=G(p)$.

Definition 5.25 Let $\left(X, \tau_{X}, A\right)$ and $\left(Y, \tau_{Y}, B\right)$ be two soft topological spaces, $x \in X$, and $e: A \rightarrow B$. A map $f: X \rightarrow Y$ is called soft $e$ - $\theta$-continuous at the point $x$ if for every $a \in$ $A$ and every $e(a)$-soft open neighborhood $(G, B)$ of $f(x)$ in $\left(Y, \tau_{Y}, B\right)$ there exists an $a$-soft open neighborhood $(F, A)$ of $x$ in $\left(X, \tau_{X}, A\right)$ such that

$$
\Phi_{f e}(\mathrm{Cl}(F, A)) \sqsubseteq \mathrm{Cl}(G, B) .
$$

If the map $f$ is soft $e$ - $\theta$-continuous at any point $x \in X$, then we say that the map $f$ is soft $e$ - $\theta$-continuous.

Proposition 5.26 Let $\left(X, \tau_{X}, A\right)$ and $\left(Y, \tau_{Y}, B\right)$ be two soft topological spaces and $e: A \rightarrow B$. If a map $f: X \rightarrow Y$ is soft $e$-continuous, then $f$ is soft $e$ - $\theta$-continuous.

Proof. Let $x \in X, a \in A$, and $(G, B)$ be an $e(a)$-soft open neighborhood of $f(x)$ in $\left(Y, \tau_{Y}, B\right)$. Since the map $f: X \rightarrow Y$ is soft $e$-continuous at $x$, there exists an $a$-soft open neighborhood $(F, A)$ of $x$ in $\left(X, \tau_{X}, A\right)$ such that

$$
\Phi_{f e}(F, A) \sqsubseteq(G, B) .
$$

By Proposition 2.18 we have

$$
\Phi_{f e}(\mathrm{Cl}(F, A)) \sqsubseteq \mathrm{Cl}\left(\Phi_{f e}(F, A)\right) .
$$

Thus,

$$
\Phi_{f e}(\mathrm{Cl}(F, A)) \sqsubseteq \mathrm{Cl}(G, B)
$$

and, therefore, the map $f$ is soft $e$ - $\theta$-continuous at the point $x$.

Example 5.27 Let $X=\{1,2, \ldots\}, A=\{0,1,2\}$,

$$
\tau_{1}=\left\{\left(G_{n}, A\right): n \in\{1,2, \ldots\}\right\} \cup\left\{\mathbf{0}_{A}, \mathbf{1}_{A}\right\},
$$

where $G_{n}(p)=\{n, n+1, \ldots\}$, for every $p \in A$, and

$$
\tau_{2}=\left\{\mathbf{0}_{A}, \mathbf{1}_{A}\right\}
$$

Then, the triplets $\left(X, \tau_{1}, A\right)$ and $\left(X, \tau_{2}, A\right)$ are soft topological spaces. We consider the map $f:\left(X, \tau_{1}, A\right) \rightarrow\left(X, \tau_{2}, A\right)$ such that $f(x)=3$, for every $x \in X$ and the map $e: A \rightarrow A$ such that $e(a)=a$, for every $a \in A$. Since $\left(\tau_{1}\right)_{\theta}=\left\{\mathbf{0}_{A}, \mathbf{1}_{A}\right\}$, the map $f$ is soft $e-\theta$-continuous. But the map $f$ is not soft $e$-continuous.

Proposition 5.28 Let $\left(X, \tau_{X}, A\right)$ and $\left(Y, \tau_{Y}, B\right)$ be two soft spaces, $x \in X, e: A \rightarrow B$, and $f: X \rightarrow Y$. If for every $a \in$ $A$ and every $e(a)$-soft open neighborhood $(G, B)$ of $f(x)$ in $\left(Y, \tau_{Y}, B\right)$ there exists an $a$ - $\theta$-soft open neighborhood
$(F, A)$ of $x$ in $\left(X, \tau_{X}, A\right)$ such that $\Phi_{f e}(F, A) \sqsubseteq \mathrm{Cl}(G, B)$, then $f$ is soft $e-\theta$-continuous at $x$.

Proof. Let $a \in A$ and $(G, B)$ be an $e(a)$-soft open neighborhood of $f(x)$. Then, there exists an $a$ - $\theta$-soft open neighborhood $(F, A)$ of $x$ in $\left(X, \tau_{X}, A\right)$ such that $\Phi_{f e}(F, A) \sqsubseteq \mathrm{Cl}(G, B)$. By Proposition 5.24 there exists an $a$-soft open neighborhood $\left(F_{(a, x)}, A\right)$ of $x$ such that $\mathrm{Cl}\left(F_{(a, x)}, A\right) \sqsubseteq(F, A)$. Thus, by Proposition 2.8,

$$
\Phi_{f e}\left(\mathrm{Cl}\left(F_{(a, x)}, A\right)\right) \sqsubseteq \Phi_{f e}(F, A) \sqsubseteq \mathrm{Cl}(G, B)
$$

and, therefore, the map $f$ is soft $e-\theta$-continuous at the point $x$.

Proposition 5.29 Let $\left(X, \tau_{X}, A\right)$ and $\left(Y, \tau_{Y}, B\right)$ be two soft topological spaces, $e: A \rightarrow B$, and $f: X \rightarrow Y$. If $\Phi_{f e}^{-1}(\mathrm{Cl}(G, B)) \in\left(\tau_{X}\right)_{\theta}$, for every $(G, B) \in \tau_{Y}$, then $f$ is soft $e-\theta$-continuous.

Proof. Let $x \in X$. By Proposition 5.28 it suffices to prove that for every $a \in A$ and every $e(a)$-soft open neighborhood $(G, B)$ of $f(x)$ in $\left(Y, \tau_{Y}, B\right)$ there exists an $a$ - $\theta$-soft open neighborhood $(F, A)$ of $x$ in $\left(X, \tau_{X}, A\right)$ such that $\Phi_{f e}(F, A) \sqsubseteq \mathrm{Cl}(G, B)$. Let $a \in A$ and $(G, B)$ be an $e(a)$-soft open neighborhood of $f(x)$ in $\left(Y, \tau_{Y}, B\right)$. Then, $f(x) \in G(e(a))$ or

$$
x \in f^{-1}(G(e(a))) \subseteq f^{-1}(\operatorname{cl}(G, e(a))) .
$$

We set $(F, A)=\Phi_{f e}^{-1}(\mathrm{Cl}(G, B))$. This means that $F(p)=$ $f^{-1}(\operatorname{cl}(G, e(p)))$, for every $p \in A$. Thus,

$$
x \in f^{-1}(\operatorname{cl}(G, e(a)))=F(a) .
$$

Since $(F, A) \in\left(\tau_{X}\right)_{\theta}$, the soft set $(F, A)$ is an $a$ - $\theta$-soft open neighborhood of $x$ in $\left(X, \tau_{X}, A\right)$. By Proposition 2.8,

$$
\Phi_{f e}(F, A)=\Phi_{f e}\left(\Phi_{f e}^{-1}(\mathrm{Cl}(G, B)) \sqsubseteq \mathrm{Cl}(G, B) .\right.
$$

Therefore, the map $f: X \rightarrow Y$ is soft $e$ - $\theta$-continuous at the point $x$.

Corollary 5.30 Let $\left(X, \tau_{X}, A\right)$ and $\left(Y, \tau_{Y}, B\right)$ be two soft topological spaces, $e: A \rightarrow B$, and $f: X \rightarrow Y$. If $\Phi_{f e}^{-1}(Q, B) \in\left(\tau_{X}\right)_{\theta}^{c}$, for every $(Q, B) \in \tau_{Y}^{c}$, then $f$ is soft $e-\theta$-continuous.

Proof. By Proposition 5.29 it suffices to prove that

$$
\Phi_{f e}^{-1}(\mathrm{Cl}(G, B)) \in\left(\tau_{X}\right)_{\theta}
$$

for every $(G, B) \in \tau_{Y}$. Let $(G, B) \in \tau_{Y}$. Then, $(G, B)^{c} \in \tau_{Y}^{c}$. By Proposition 2.8 we have

$$
\Phi_{f e}^{-1}\left((G, B)^{c}\right)=\left(\Phi_{f e}^{-1}(G, B)\right)^{c} .
$$

Since $\Phi_{f e}^{-1}\left((G, B)^{c}\right) \in\left(\tau_{X}\right)_{\theta}^{c}$, we have $\Phi_{f e}^{-1}(G, B) \in\left(\tau_{X}\right)_{\theta}$.

Proposition 5.31 If the map $f: X \rightarrow Y$ is soft $e-\theta$-continuous, then

$$
\Phi_{f e}\left(\mathrm{Cl}_{\theta}(F, A)\right) \sqsubseteq \mathrm{Cl}_{\theta}\left(\Phi_{f e}(F, A)\right)
$$


for every $(F, A) \in \mathrm{SS}(X, A)$.

Proof. Let $\Phi_{f e}\left(\mathrm{Cl}_{\theta}(F, A)\right)=(Q, B) \in \mathrm{SS}(Y, B)$, where

$$
Q\left(p_{Y}\right)=\left\{\begin{array}{l}
\bigcup\left\{f\left(\operatorname{cl}_{\theta}(F, p)\right): p \in e^{-1}\left(\left\{p_{Y}\right\}\right)\right\} \\
\text { if } e^{-1}\left(\left\{p_{Y}\right\}\right) \neq \emptyset \\
\emptyset, \text { if } e^{-1}\left(\left\{p_{Y}\right\}\right)=\emptyset
\end{array}\right.
$$

for every $p_{Y} \in B$ and $\Phi_{f e}(F, A)=\left(Q^{\prime}, B\right) \in \mathrm{SS}(Y, B)$, where

$$
Q^{\prime}\left(p_{Y}\right)=\left\{\begin{array}{l}
\bigcup\left\{f(F(p)): p \in e^{-1}\left(\left\{p_{Y}\right\}\right)\right\} \\
\text { if } e^{-1}\left(\left\{p_{Y}\right\}\right) \neq \emptyset \\
\emptyset, \text { if } e^{-1}\left(\left\{p_{Y}\right\}\right)=\emptyset
\end{array}\right.
$$

for every $p_{Y} \in B$. It suffices to prove that $(Q, B) \sqsubseteq \mathrm{Cl}_{\theta}\left(Q^{\prime}, B\right)$ or equivalently $Q\left(p_{Y}\right) \subseteq \mathrm{cl}_{\theta}\left(Q^{\prime}, p_{Y}\right)$, for every $p_{Y} \in B$. Let $p_{Y} \in B$. If $e^{-1}\left(\left\{p_{Y}\right\}\right)=\emptyset$, then $Q\left(p_{Y}\right)=\operatorname{cl}_{\theta}\left(Q^{\prime}, p_{Y}\right)=\emptyset$. We suppose that $e^{-1}\left(\left\{p_{Y}\right\}\right) \neq \emptyset$. Let $y \in Q\left(p_{Y}\right)$. Then, there exists $p \in e^{-1}\left(\left\{p_{Y}\right\}\right)$ such that $y \in f\left(\operatorname{cl}_{\theta}(F, p)\right)$. Let $y=f(x)$, where $x \in \operatorname{cl}_{\theta}(F, p)$. We prove that $y \in \operatorname{cl}_{\theta}\left(Q^{\prime}, p_{Y}\right)$. Let $(G, B)$ be a $p_{Y}$-soft open neighborhood of $y$. It suffices to prove that $\left(Q^{\prime}, B\right) \sqcap \mathrm{Cl}(G, B) \neq \mathbf{0}_{B}$. Since $p_{Y}=e(p)$ and the map $f$ is soft $e-\theta$-continuous at the point $x$, there exists a $p$-soft open neighborhood $(H, A)$ of $x$ in $\left(X, \tau_{X}, A\right)$ such that

$$
\Phi_{f e}(\mathrm{Cl}(H, A)) \sqsubseteq \mathrm{Cl}(G, B) .
$$

Since $x \in \operatorname{cl}_{\theta}(F, p)$, we have $(F, A) \sqcap \mathrm{Cl}(H, A) \neq \mathbf{0}_{A}$. Therefore, by Proposition 2.8 we have

$$
\begin{aligned}
\mathbf{0}_{B} & \neq \Phi_{f e}((F, A) \sqcap \mathrm{Cl}(H, A)) \\
& \sqsubseteq \Phi_{f e}(F, A) \sqcap \Phi_{f e}(\mathrm{Cl}(H, A)) \\
& =\left(Q^{\prime}, B\right) \sqcap \Phi_{f e}(\mathrm{Cl}(H, A)) .
\end{aligned}
$$

Thus, $\left(Q^{\prime}, B\right) \sqcap \Phi_{f e}(\mathrm{Cl}(H, A)) \neq \mathbf{0}_{B}$ and, therefore, by relation (1) we have $\left(Q^{\prime}, B\right) \sqcap \mathrm{Cl}(G, B) \neq \mathbf{0}_{B}$.

Corollary $\mathbf{5 . 3 2}$ If the map $f: X \rightarrow Y$ is soft $e-\theta$-continuous, then

$$
\mathrm{Cl}_{\theta}\left(\Phi_{f e}^{-1}(G, B)\right) \sqsubseteq \Phi_{f e}^{-1}\left(\mathrm{Cl}_{\theta}(G, B)\right),
$$

for every $(G, B) \in \mathrm{SS}(Y, B)$.

Proof. By Proposition 5.31 and Proposition 2.8 we have

$$
\begin{aligned}
\Phi_{f e}\left(\mathrm{Cl}_{\theta}\left(\Phi_{f e}^{-1}(G, B)\right)\right) & \sqsubseteq \mathrm{Cl}_{\theta}\left(\Phi_{f e}\left(\Phi_{f e}^{-1}(G, B)\right)\right) \\
& \sqsubseteq \mathrm{Cl}_{\theta}(G, B) .
\end{aligned}
$$

Therefore,

$$
\begin{aligned}
\mathrm{Cl}_{\theta}\left(\Phi_{f e}^{-1}(G, B)\right) & \sqsubseteq \Phi_{f e}^{-1}\left(\Phi_{f e}\left(\mathrm{Cl}_{\theta}\left(\Phi_{f e}^{-1}(G, B)\right)\right)\right) \\
& \sqsubseteq \Phi_{f e}^{-1}\left(\mathrm{Cl}_{\theta}(G, B)\right) .
\end{aligned}
$$

Proposition 5.33 If the map $f: X \rightarrow Y$ is soft $e-\theta$-continuous, then

$$
\Phi_{f e}^{-1}(G, B) \sqsubseteq \operatorname{Int}_{\theta}\left(\Phi_{f e}^{-1}\left(\mathrm{Cl}_{\theta}(G, B)\right)\right),
$$

for every $(G, B) \in \tau_{Y}$.

Proof. Let $\Phi_{f e}^{-1}(G, B)=(F, A) \in \mathrm{SS}(X, A)$, where

$$
F(p)=f^{-1}(G(e(p))), \text { for every } p \in A
$$

and $\Phi_{f e}^{-1}\left(\mathrm{Cl}_{\theta}(G, B)\right)=\left(F^{\prime}, A\right) \in \mathrm{SS}(X, A)$, where

$$
F^{\prime}(p)=f^{-1}\left(\operatorname{cl}_{\theta}(G, e(p))\right) \text {, for every } p \in A .
$$

We prove that

$$
(F, A) \sqsubseteq \operatorname{Int}_{\theta}\left(F^{\prime}, A\right)
$$

or equivalently $F(p) \subseteq \operatorname{int}_{\theta}\left(F^{\prime}, p\right)$, for every $p \in A$. Let $p \in A$ and $x \in F(p)$. It suffices to prove that $x \in \operatorname{int}_{\theta}\left(F^{\prime}, p\right)$. We have $f(x) \in G(e(p))$. Since the map $f$ is soft $e$ - $\theta$-continuous at the point $x$, there exists a $p$-soft open neighborhood $(H, A)$ of $x$ in $\left(X, \tau_{X}, A\right)$ such that

$$
\Phi_{f e}(\mathrm{Cl}(H, A)) \sqsubseteq \mathrm{Cl}(G, B) .
$$

We prove that $\mathrm{Cl}(H, A) \sqsubseteq\left(F^{\prime}, A\right)$. Indeed, by relation (2) and Proposition 2.8 we have

$$
\begin{aligned}
\mathrm{Cl}(H, A) & \sqsubseteq \Phi_{f e}^{-1}\left(\Phi_{f e}(\mathrm{Cl}(H, A))\right) \sqsubseteq \Phi_{f e}^{-1}(\mathrm{Cl}(G, B)) \\
& \sqsubseteq \Phi_{f e}^{-1}\left(\mathrm{Cl}_{\theta}(G, B)\right)=\left(F^{\prime}, A\right) .
\end{aligned}
$$

\section{Questions}

1. Is the converse of Propositions 3.11, 3.16, 3.17, and 5.33 true?

2. Let $(X, \tau, A)$ be a soft topological space. Under what conditions does the equality $\tau_{\theta}=\tau$ hold?

3. Let $(X, \tau, A)$ be a soft topological space. Under what conditions does the sequence $\tau, \tau_{\theta},\left(\tau_{\theta}\right)_{\theta},\left(\left(\tau_{\theta}\right)_{\theta}\right)_{\theta}, \ldots$ is eventually constant?

4. Find a soft topological space $(X, \tau, A)$ such that

$$
\tau \supsetneqq \tau_{\theta} \supsetneqq\left(\tau_{\theta}\right)_{\theta} \supsetneqq\left(\left(\tau_{\theta}\right)_{\theta}\right)_{\theta} \supsetneqq \ldots
$$

\section{Conclusion}

The classical mathematical theories have their difficulties which are pointed out in [18] for the solution complicated problems in engineering and environment. To overcome these difficulties, Molodtsov [18] introduced the concept of soft set as a new mathematical tool. Furthermore, D. Pei and D. Miao [22] showed that soft sets are a class of special information systems.

Topology is an important area of mathematics with many applications in the domains of computer science and physical sciences. Soft topology is a relatively new and promising domain which can lead to the development of new mathematical models and innovative approaches 
that will significantly contribute to the solution of complex problems in natural sciences.

In [9] for the soft set theory: new definitions, examples, new classes of soft sets, and properties for mappings between different classes of soft sets are introduced and studied. Moreover, the theory of soft topological spaces is investigated.

This paper continues the study of the theory of soft topological spaces. In section 2 we give known basic notions and results concerning the theory of soft sets and soft topological spaces. In section 3 we present separation axioms and we investigate the notion of convergence. In section 4 the Cartesian product of two soft topological spaces is studied. In section 5 we introduce and study notions concerning the soft $\theta$-open sets, the soft $\theta$-closed sets, and the soft $\theta$-continuity. Finally, in section 6 we give some questions on soft topological spaces.

Acknowledgements. We are grateful to the reviewer for a number of helpful suggestions for improvement in the article.

\section{References}

[1] H. Aktaş and N. Çağman, Soft sets and soft groups, Information Sciences, 177, 2726-2735 (2007).

[2] M. I. Ali, F. Feng, X. Liu, W. K. Min, and M. Shabir, On some new operations in soft set theory, Comput. Math. Appl., 57, 1547-1553 (2009).

[3] A. Aygunoglu and H. Aygun, Some notes on soft topological spaces, Neural. Comput. Appl., 1-7 (2011).

[4] N. Çağman and S. Enginoglu, Soft set theory and uniint decision making, European J. Oper. Res., 207, 848-855 (2010).

[5] N. Çağman and S. Enginoglu, Soft matrix theory and its decision making, Comput. Math. Appl., 59, 3308-3314 (2010).

[6] N. Çağman, S. Karataş, and S. Enginoglu, Soft topology, Comput. Math. Appl., 62, 351-358 (2011).

[7] D. Chen, E. C. C. Tsang, D. S. Yeung, and X. Wang, The parameterization reduction of soft sets and its applications, Comput. Math. Appl., 49, 757-763 (2005).

[8] Feng Feng, Young Bae Jun, Xianzhong Zhao, Soft semirings, Computers \& Mathematics with Applications, 56, 2621-2628 (2008).

[9] D. N. Georgiou and A. C. Megaritis, Soft Set Theory and Topology, Applied General Topology, 14, (2013).

[10] S. Hussain and B. Ahmad, Some properties of soft topological spaces, Comput. Math. Appl., 62, 4058-4067 (2011).

[11] O. Kazanci, S. Yilmaz, and S. Yamak, Soft Sets and Soft BCH-Algebras, Hacettepe Journal of Mathematics and Statistics, 39, 205-217 (2010).

[12] Athar Kharal and B. Ahmad, Mappings of soft classes, to appear in New Mathematics and Natural Computation.

[13] P. K. Maji, A. R. Roy, and R. Biswas, An application of soft sets in a decision making problem, Comput. Math. Appl., 44, 1077-1083 (2002).
[14] P. K. Maji, R. Biswas, and A. R. Roy, Soft set theory, Comput. Math. Appl., 45, 555-562 (2003).

[15] P. K. Maji, R. Biswas, and A. R. Roy, Fuzzy soft sets, J. Fuzzy Math., 9, 589-602 (2001).

[16] P. Majumdar and S. K. Samanta, Similarity measure of soft sets, New. Math. Nat. Comput., 4, 1-12 (2008).

[17] W. K. Min, A note on soft topological spaces, Comput. Math. Appl., 62, 3524-3528 (2011).

[18] D. A. Molodtsov, Soft set theory-first results, Comput. Math. Appl., 37, 19-31 (1999).

[19] D. A. Molodtsov, The description of a dependence with the help of soft sets, J. Comput. Sys. Sc. Int., 40, 977-984 (2001).

[20] D. A. Molodtsov, The theory of soft sets (in Russian), URSS Publishers, Moscow, (2004).

[21] D. A. Molodtsov, V. Y. Leonov, and D. V. Kovkov, Soft sets technique and its application, Nechetkie Sistemy i Myagkie Vychisleniya, 1, 8-39 (2006).

[22] D. Pei and D. Miao, From soft sets to information systems, In: X. Hu, Q. Liu, A. Skowron, T. Y. Lin, R. R. Yager, B. Zhang ,eds., Proceedings of Granular Computing, IEEE, 2, 617-621 (2005).

[23] E. Peyghan, B. Samadi, A. Tayebi, About soft topological spaces, Topology and its Applications, In Press, (2012).

[24] M. Shabir and M. Naz, On soft topological spaces, Comput. Math. Appl., 61, 1786-1799 (2011).

[25] Yingchao Shao, Keyun Qin, The lattice structure of the soft groups, Procedia Engineering, 15, 3621-3625 (2011).

[26] I. Zorlutuna, M. Akdag, W. K. Min, and S. Atmaca, Remarks on soft topological spaces, Annals of Fuzzy Mathematics and Informatics, 3, 171-185 (2012).

[27] Y. Zou and Z. Xiao, Data analysis approaches of soft sets under incomplete information, Knowl. Base. Syst., 21, 941945 (2008). 


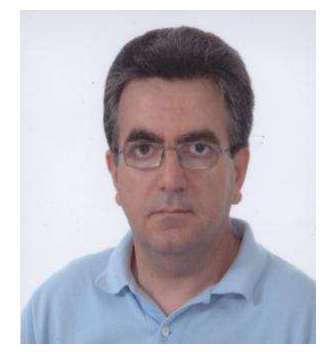

$\begin{array}{lrr}\text { Dimitris } & \text { Georgiou } \\ \text { is } & \text { Associate } & \text { Professor } \\ \text { of } & \text { Department } & \text { of }\end{array}$ Mathematics at University of Patras of Greece and he received the $\mathrm{PhD}$ degree in Pure Mathematics. His research interests are in the areas of pure and applied mathematics. He is referee and Editor of several international journals in the frame of pure and applied mathematics. He has published research articles in international journals of mathematical sciences.

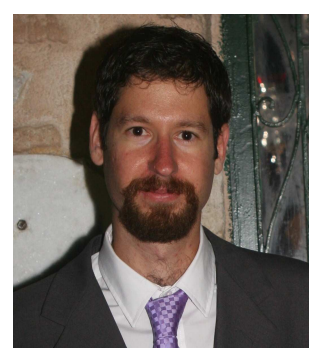

Athanasios Megaritis received the $\mathrm{PhD}$ degree in Pure Mathematics at University of Patras of Greece. His research interests are in the areas of pure and applied mathematics. He has published research articles in international journals of mathematical sciences. Also, he is referee of mathematical journals.

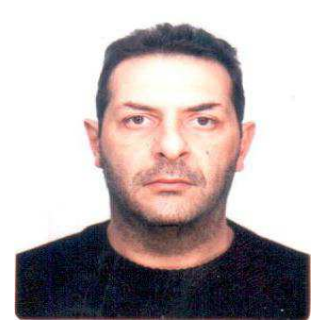

Vasilios Petropoulos received the Master's degree in Pure Mathematics at University of Patras of Greece. His research interests are in the areas of pure and applied mathematics. 